\title{
Selenium and selenoproteins: it's role in regulation of inflammation
}

\author{
Sneha Hariharan ${ }^{1} \cdot$ Selvakumar Dharmaraj ${ }^{1}$ \\ Received: 6 July 2019 / Accepted: 6 February 2020 / Published online: 6 March 2020 \\ (c) Springer Nature Switzerland AG 2020
}

\begin{abstract}
Selenium is an essential immunonutrient which holds the human's metabolic activity with its chemical bonds. The organic forms of selenium naturally present in human body are selenocysteine and selenoproteins. These forms have a unique way of synthesis and translational coding. Selenoproteins act as antioxidant warriors for thyroid regulation, male-fertility enhancement, and anti-inflammatory actions. They also participate indirectly in the mechanism of wound healing as oxidative stress reducers. Glutathione peroxidase (GPX) is the major selenoprotein present in the human body, which assists in the control of excessive production of free radical at the site of inflammation. Other than GPX, other selenoproteins include selenoprotein-S that regulates the inflammatory cytokines and selenoprotein-P that serves as an inducer of homeostasis. Previously, reports were mainly focused on the cellular and molecular mechanism of wound healing with reference to various animal models and cell lines. In this review, the role of selenium and its possible routes in translational decoding of selenocysteine, synthesis of selenoproteins, systemic action of selenoproteins and their indirect assimilation in the process of wound healing are explained in detail. Some of the selenium containing compounds which can acts as cancer preventive and therapeutics are also discussed. These compounds directly or indirectly exhibit antioxidant properties which can sustain the intracellular redox status and these activities protect the healthy cells from reactive oxygen species induced oxidative damage. Although the review covers the importance of selenium/selenoproteins in wound healing process, still some unresolved mystery persists which may be resolved in near future.
\end{abstract}

Selvakumar Dharmaraj

biochem_selva@yahoo.com; sdharmaraj77@gmail.com

1 Department of Biochemistry, Karpagam Academy of Higher Education, Eachanari Post, Pollachi Main Road, Coimbatore, Tamil Nadu 641021, India 


\section{Graphic abstract}

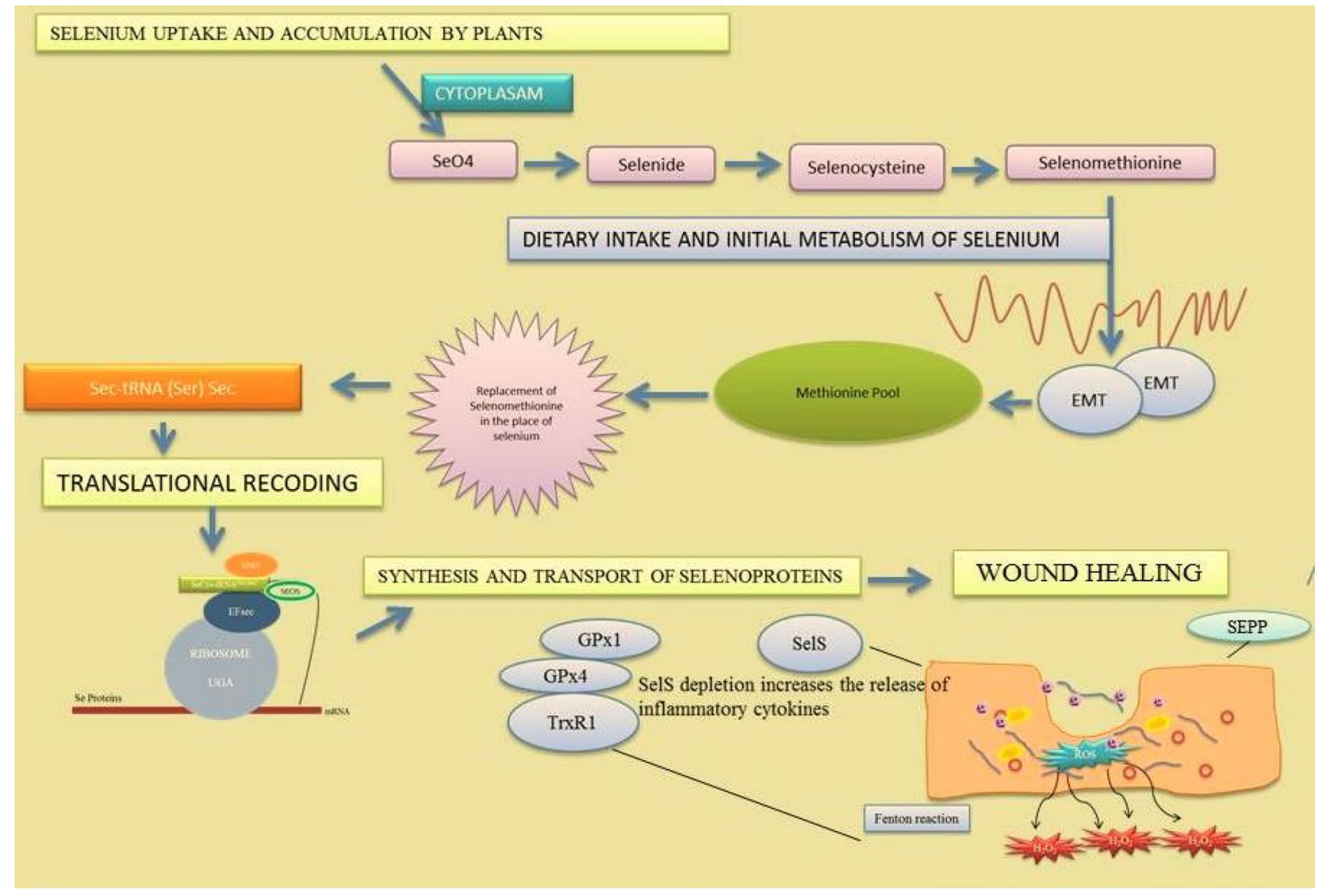

Keywords Selenium $\cdot$ Selenoproteins $\cdot$ Wound healing $\cdot$ Selenium drugs $\cdot$ Gpxs $\cdot$ SEPP1 $\cdot$ SEPS1 $\cdot$ ROS

\section{Introduction}

Selenium is an essential trace element which possesses the symbol Se with atomic number 34 in the periodic table. Selenium was discovered by Swedish chemist Jons Jacob Berzelius in the year 1817 and it was named after the ancient Greek word 'Selene' which refers to Moon. Selenium is a reactive nonmetal or metalloid located in P Block, Period IV and Group 16 of the Mendeleev's periodic table of elements. Selenium originates from Sulfide ore which partially replaces the Sulphur in certain reactions since it possesses similar physical and chemical properties of Sulphur (Meija et al. 2016). Selenium is an amorphous brick red powder and when it reaches its melting point, it tends to turn into its black vitreous form. It has six different isotopes with varied stabilization states, half-life and mode of decay. Selenium exists in two different forms, namely organic and inorganic. Organic forms of selenium are present as selenocysteine and selenomethionine in human body. Inorganic forms such as selenite and selenate get accumulated in plants through soil. Selenium has the ability to combine with other minerals and elements of Sulphide, Copper, Silver, Nickel and Lead. Selenium holds the 67th rank for the most abundant element on the Earth's crust (USEPA 2014).

Selenium is the most required micronutrient for human beings and animals. Inorganic selenium is mostly accumulated in plants via Sulphur assimilation pathway, whereas animals and humans consume these sources later as vegetables, meats and dietary supplements. The level of Se concentration in plants differs by the type of soil, level of accumulation capacity, $\mathrm{pH}$, salinity, organic matter, redox reactions, and type of plant species. Excessive accumulation of selenium in plants leads to toxicity (Drahoňovský et al. 2014). The selenium content in soil differs globally and when it is compared with other nations, the Indian and European soils possess less selenium (Rayman 2008). Daily intake of selenium is highly recommended for maintaining the natural metabolism and homeostasis in the human body. 
The intake dosage of selenium is determined as $55 \mu \mathrm{g}$ and $70 \mu \mathrm{g}$ per day for adult males and females, respectively. Selenium consumption is mostly dependent on the food contents and dietary supplements (Navarro-Alarcon and CabreraVique 2008).

Seafoods and meats are first to be placed in the selenium rich foods. The other selenium rich foods include muscle meats, cereals, grains and dairy products. The amount of selenium in drinking water is not nutritionally significant in most geographic regions. As a result, selenium concentrations in water cannot be considered as selenium supplementation. However, selenium concentration in soil has a reduced effect in animal products than in plant-based foods because animals maintain predictable tissue concentrations of selenium through homeostatic mechanisms (Chun et al. 2009).

Selenium is an essential component for many enzymes' activities. It has been widely experimented for its crucial role as an antioxidant and in immunological cycles, where it can be incorporated non-specifically with the amino acid Methionine in body proteins. Skeletal muscle is the major site of selenium storage, accounting for approximately $28-46 \%$ of the total selenium pool (Pascual and Aranda 2013). Selenium has several promising roles in the human body such as antioxidant, anti-inflammatory, anti-mutagenic, anti-carcinogenic, antiviral, antibacterial and antifungal effects (Rayman 2000; Cihalova et al. 2015; Shakibaie et al. 2015; Malhotra et al. 2016; Peng et al. 2016; Stolzoff and Webster 2016; Maiyo and Singh 2017).

Selenium is the integral compound of selenoproteins in the human body; the selenoprotein family consists of 25 eukaryotic genes where 25 are human genes and 24 are mouse genes. All these proteins have selenocysteine residue in their primary predefined structure (Kryukov et al. 2003). Selenium has a specific protein synthesis pathway where its codes for the 21 st amino acid called UGA Codon; this process is called as Translational Decoding (Bubenik et al. 2014). These selenoproteins are responsible for function and regulation of thyroid hormones, regulators of growth, development and differentiation, inhibitors of non-specific immune response, neutralisers of inflammatory, chemotactic and phagocytic responses like anti-male sterility, reproduction and oxidative stress influencer (Schomburg 2012; Dentice et al. 2013; Pascual and Aranda 2013; Effraimidis and Wiersinga 2014; Zubair et al. 2015; Chan et al. 2016). Role of selenium in human body is important and crucial in stabilising and neutralising the body metabolism. During wound healing process, certain selenoproteins like GPX-1, GPX4 , selenoprotein $\mathrm{S}$ and selenoprotein $\mathrm{P}$ combine to perform various reactions such as antioxidant activities, inhibition of inflammatory cytokines and elimination of Peroxynitrate (a super radical ion) in inflammatory phase (Lei et al. 2009; Cox et al. 2013; Talbi et al. 2019).
Wound healing is a complex process with many cascades of events involving different phases, such as (1) haemostasis or blood clotting, (2) inflammation, (3) proliferation and (4) remodelling or maturation. A wound is defined as disruption or damage to the normal cells which changes the anatomical structure and function. Wounds can be classified according to their shape, depth and infection (Coupland 1992). The Centre for disease control and prevention (CDC) categorised the surgical wounds into three types by clean, contaminated, and infected. Primarily the wound is classified into three types (1) acute (2) chronic and (3) complicated. Acute wounds heal themselves in accordance with proper duration and follows orderly healing pathway; the duration of healing normally ranges either from 5 to 10 days nor within a month. Chronic wounds are wounds that cannot be restored normally by healing pathway; they have irregular duration and prolonged process like infection, necrosis, hypoxia, and higher amount of inflammatory cytokine release. The combination of tissue disintegration and infection is termed to be complicated wound. For example: tumor cell in a complicated region such as brain, oesophagus, uterus, etc. (Lazarus et al. 1994; Bischoff et al. 1999).

Skin is the first line of defense which covers the entire body, safeguarding it from the external environment. The skin protects the body from pathogens, harmful rays, foreign invaders, and oxidative stress. Apart from that, it also possesses functions like maintaining the body temperature, immunological reactions, regulations of specific metabolic reactions, and many signalling activities. An injury starts with tissue disintegration followed by bleeding which helps to flush out the blood containing microbes and foreign particles. Immediately the clotting factors trigger the phases of coagulation and haemostasis which leads to platelet aggregation and fibrinogen formation (Martin et al. 1997; Sen 2009). The inflammatory phase which deals with cellular and vascular responses usually starts within few minutes of the injury and lasts up to $24 \mathrm{~h}$. In migration phase, the epithelial cells and fibroblasts migrate towards the injured area to replace the disintegrated, damaged cells and tissues. On day 3 , the proliferation phase starts with granulation for tissue formation, synthesis of lymphatic vessels, synthesis of collagen by fibroblasts, and maximum formation of blood vessels and tissues. The final phase of wound healing is said to be maturation or remodelling which involves the regeneration of cellular connective tissues and strengthening of the new epithelium. This prolonged process may take months to 2 years to recover fully (Velnar et al. 2009). As discussed above, certain selenoproteins act as antioxidants as well as inducers during specific phases of wound healing process. In this review, we try to elucidate some of the possible routes in which selenoproteins participate in wound healing mechanism. 


\section{Selenium uptake and accumulation by plants}

Selenium is one of the important elements needed for plant growth and development. The major physiological role of selenium in plant is to prevent oxidative stress, phytoremediation, biofortification, etc. Plants are classified into two major types based on the level of selenium accumulation. Certain plants grown in selenium enriched soil tend to accumulate high levels of the element; they are called as hyper accumulators or Se-tolerant plants. The plants that do not accumulate selenium are known as hypo accumulators or SeSensitive plants (Zhu et al. 2009; Yu and Gu 2013; Alfthan et al. 2015; El-Ramady et al. 2015). The major plant species that are hyper accumulators come under the families of Brassicaceae, Fabaceae and Asteraceae (Läuchli 1993). These hyper accumulator plants store organic forms of selenium such as methyl-SeCysteine and selenocysteine, whereas hypo accumulators store inorganic selenium (De Souza et al. 1998). The physiological cycle of plant uptake and accumulation of selenium is clearly shown in Fig. 1.
Selenium competes with Sulphur through Sulphur transport channels by a process called Sulphur assimilation pathway which leads to the formation of two major components mainly selenocysteine, selenomethionine and other organic selenium derivatives (Stadtman 1990). The major events of physiological process are conversion of selenate to selenite, selenide followed by selenocysteine. Some species of plants metabolise selenomethionine into volatile dimethylselenide (DMSe) which helps to reduce toxicity (Terry et al. 2000). With the help of Sec selenocysteine Lyase, the selenocysteine gets converted to elemental selenium and Alanine (Domokos-Szabolcsy et al. 2012). Methylation process takes place when selenocysteine gets converted into Se-Cystathionine by Cystathionine gamma synthase and Ortho-Phospho Hemoserine (OPH) coupling. This helps in the Se detoxification process (Neuhierl and Böck 1996).

\section{Selenium in foods}

Selenium has several chemical derivatives such as selenomethionine, selenocysteine, selenate and selenite. These are the major sources of dietary selenium of which the most widely

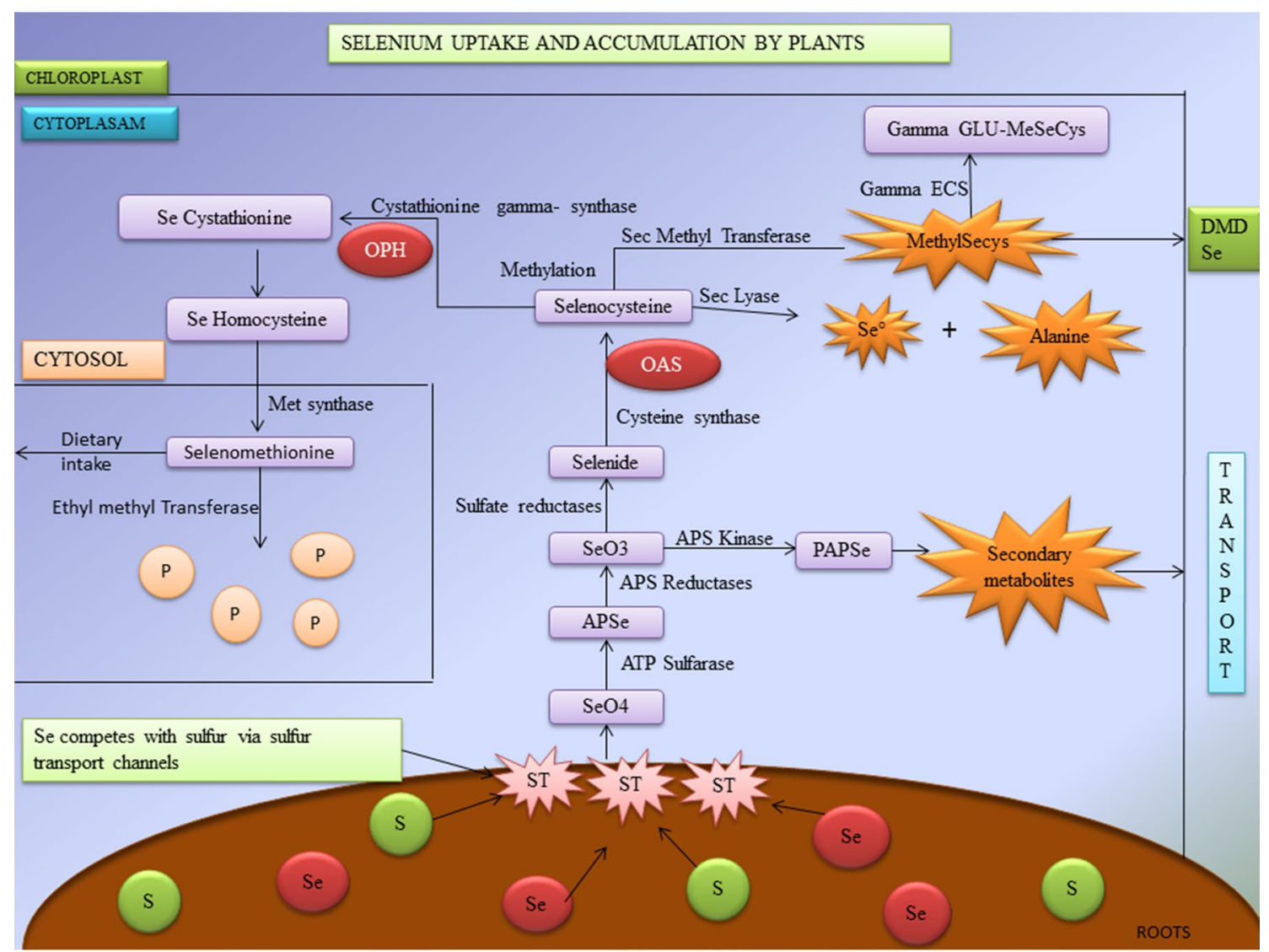

Fig. 1 Selenium uptake and accumulation in plants (ST Sulfur transport channels, $\mathrm{SeO}_{4}$ selenate, $\mathrm{APSe}$ adenosine phosposelenate, PAPSe phospho adenosine phospho selenite, $O A S O$-acetyl serine, $O P H$
$O$-phospho hemoserine, $D M S e$ dimethylselenide; products are shown in purple color. Metabolites are shown in orange color) 
consumed is selenomethionine. The major administration of selenium supplementation is via food. The level of selenium in each diet depends upon the plant uptake level. Hyper accumulator plants contain higher amount of selenium concentration and vice versa (Rayman 2008). Foods that contribute to major selenium sources include cereals, breads, millets, wheat, nuts, meats, eggs, etc. Mushrooms, Brazil nuts and Broccoli are determined to have higher amount of selenium accumulation (Hart et al. 2011; Banuelos et al. 2013). The selenium concentrations in various foods are detailed in Table 1.

Approximately $20 \mu \mathrm{g}$ per day is minimal RDA of selenium for adults to prevent Keshan disease. Keshan disease is a dilated cardiomyopathy (abnormality of the heart muscle) which was first found in "Keshan County" of North East China Provinces. This disease is characterised by multifocal myocardial necrosis and fibrosis which leads to cardiogenic shock and congestive heart failure. The normal intake of selenium should be about $50-55 \mu \mathrm{g}$ per day. The dietary recommendations and regulations may differ across geographical locations, $\mathrm{pH}$, humidity, climatic changes, and soil (Moore et al. 2000; Fairweather-Tait et al. 2010). Vegetables contain higher amount of selenomethionine, selenate, and selenite than selenocysteine. Selenomethionine is the major selenium source for humans and animals. Selenomethionine is synthesised through plants at the maximal concentration (Rayman 2002; Thomson 2004; Cubadda et al. 2010; Yasin et al. 2015). The consumption and upper level tolerance of selenium are elaborated in Tables 2 and 3.
Table 2 Nominal intake of selenium $\mu \mathrm{g} /$ per day (Vinceti et al. 2001)

\begin{tabular}{lllll}
\hline Age & Male $(\mu \mathrm{g})$ & Female $(\mu \mathrm{g})$ & $\begin{array}{l}\text { Preg- } \\
\text { nancy } \\
(\mu \mathrm{g})\end{array}$ & Lactation $(\mu \mathrm{g})$ \\
\hline Birth-6 months & 15 & 15 & - & - \\
$7-12$ months & 20 & 20 & - & - \\
$1-3$ years & 20 & 20 & - & - \\
4-8 years & 30 & 30 & - & - \\
9-13 years & 40 & 40 & - & - \\
$14-18$ years & 55 & 55 & 60 & 70 \\
$19-50$ years & 55 & 55 & 60 & 70 \\
$51+$ years & 55 & 55 & - & - \\
\hline
\end{tabular}

\section{Selenium supplements}

Because of inadequacy of selenium in soil, it is sometimes necessary for humans to take selenium supplementation. Selenium is an excellent micronutrient that is acquired through food sources like nuts, breads, cereals, meat, fish, milk, and dairy products. These supplements act as antioxidants by its radical scavenging activities and reduce the oxidative damages in different internal organs (Rahmanto and Davies 2012). Reports elucidate the selenium supplementation and its effects on HIV, Crohn's disease, Thyroid diseases, and cardiovascular diseases (Kuroki et al. 2003; Stone et al. 2010; Wu et al. 2015; Benstoem et al. 2015). The major forms of selenium supplements are Sodium selenite
Table 1 Selenium Concentrations in various food items

\begin{tabular}{llll}
\hline Sources & $\begin{array}{l}\text { Selenium concentration } \\
(\mathrm{mg} / \mathrm{kg})\end{array}$ & Major selenium species & References \\
\hline Brazil nuts & $0.03-515$ & SeMet & Hart et al. (2011) \\
Bread & $0.01-30$ & SeMet/selenate & \\
Cereals & $0.02-35$ & SeMet/selenate & \\
Rice & $0.05-0.08$ & SeMet & \\
Onions & $0.02-0.05$ & SeMet/Sec & \\
Garlic & $0.05-1.0$ & SeMet/Sec & \\
Broccoli & $0.5-1.0$ & SeMet/selenate & Banuelos et al. (2013) \\
Potatoes & 0.12 & SeMet & \\
Lentils & $0.24-0.36$ & SeMet/selenate & \\
Meat and meat products & & \\
Beef & $0.42-0.142$ & SeMet & \\
Chicken & $0.081-0.142$ & SeMet/Sec & \\
Fish & $0.1-5.0$ & SeMet/selenite/selenate & \\
Eggs & $3-25$ & SeMet/Sec & \\
Pork & $0.032-0.198$ & SeMet/selenate & \\
Lamb & $0.033-0.260$ & SeMet & \\
Milk and dairy & $0.01-0.03$ & Sec/selenite & \\
products & & SeMet & \\
Yeast & $0.6-15$ & & \\
\hline & & & \\
\hline
\end{tabular}


Table 3 Tolerable intake levels of selenium $\mu \mathrm{g} / \mathrm{per}$ day (Vinceti et al. 2001)

\begin{tabular}{lccll}
\hline Age & Male $(\mu \mathrm{g})$ & Female $(\mu \mathrm{g})$ & Pregnancy $(\mu \mathrm{g})$ & Lactation $(\mu \mathrm{g})$ \\
\hline Birth-6 months & 45 & 45 & - & - \\
7-12 months & 60 & 60 & - & - \\
1-3 years & 90 & 90 & - & - \\
4-8 years & 150 & 150 & - & - \\
9-13 years & 280 & 280 & - & 400 \\
14-18 years & 400 & 400 & 400 & 400 \\
19+ years & 400 & 400 & 400 & \\
\hline
\end{tabular}

(inorganic), selenomethionine (organic), and selenium rich yeasts.

\section{Initial metabolism of selenium in human}

Selenomethionine is the principal chemical form of dietary selenium and its consumed widely (Diamond et al. 1993). The initial metabolism starts by ingesting the selenomethionine (SeMet) via food or supplements. The SeMet absorbed through intestinal transport channels, reaches the Methionine pool. The major function of Methionine pool is to store selenomethionine and simultaneously incorporate them into proteins replacing the position of Methionine and forming selenomethionine. One of the reports reveals that "the ratio of 1 selenium atom (SeMet) per 8000 Methionine residues is equivalent to 1 selenomethionine per 1100 albumin molecules" (Burk 2001). The selenomethionine travels through Methionine cycle and Transsulphuration pathways (mostly in liver). The selenomethionine undergoes transsulphuration to produce selenocysteine and further with the help of Sec Lyase it tends to form selenide (Martin and Hurlbut 1976; Esaki et al. 1982). During dietary intake, the consumption of selenocysteine is comparatively low than selenomethionine resulting in highly reactive selenocysteine (Sec). These are maintained at low concentration whereas the less reactive selenomethionine (SeMet) is highly metabolised (Suzuki 2005). In liver, methyl selenol is produced as a result of $\alpha$-lyase activity, and this methyl selenol in turn gets demethylated to form selenide (Suzuki et al. 2006). The major reported biological function of selenomethionine is to produce derivatives of selenium as well as to store selenomethionine for further synthesis of selenoproteins. The final step in the metabolism of selenium is the conversion of SeMet to Sec through Transsulphuration pathway followed by biosynthesis of selenoproteins (Labunskyy et al. 2014). The pathway for initial metabolism of selenium is partially explained in Fig. 2.

\section{Biosynthesis of selenoproteins}

In the year 1985, the cloning of GPX1 leads to the discovery of UGA which is a stop codon for Sec during regular translational process (Chambers et al. 1986). Sec is a recently explored eukaryotic amino acid which directly encodes into proteins forming the $21 \mathrm{st}$ amino acid. The mechanism of translational decoding or otherwise called as biosynthesis of selenoproteins is shown in Fig. 3.

During translational decoding, UGA codon is one among the three stop codons which works for mRNA in which tRNA for selenocysteine (tRNA ${ }^{\mathrm{Sec}}$ ) recognizes and attaches to the respective codon (Buettner et al. 1999). Helper amino acid Serine conjugates with tRNA ${ }^{\text {Sec }}$ by seryl-tRNA sythetase which is further phosphorylated into phosphoserine by an enzyme phosphoseryl-tRNA kinase (Ganyc et al. 2006). After the initial metabolism of selenium, the dietary selenium gets phosphorylated by selenophosphate synthase 2 (SPS2) which is then conjugated with phosphoserine by selenocysteine synthase to produce selenocysteine (Chen and Berry 2003). All eukaryotic selenoprotein genes require selenocysteine Insertion Sequence (SECIS) element in 3' UTR of the mRNA for recoding of UGA stop codon for Sec insertion. The unique stem loop structure of SECIS is the binding site of selenocysteine incorporation sequence binding protein 2 (SPB2) (Böck et al. 1991). The RNA binding domain of SPB2 (SECIS binding protein 2) belongs to L7Ae riboprotein family. SPB2 is a complex protein containing minimum of five isomers which splices alternatively around 17-19 possible exons (Papp et al. 2008). The location and functions of different selenoproteins is detailed in Table 4. Other factors include specialized elongation factor (EFsec) that gets bound to tRNA ${ }^{\mathrm{Sec}}$ for an extra protein binding support system (Squires and Berry 2008). The assembly of certain factors and cofactors on selenoprotein mRNA leads to the decoding of UGA into Sec via translational decoding process (De Jesus et al. 2006). Oxidation of SPB2 in nucleus gets reduced by nuclear specific GPX and Thioredoxin reductases (TRXR) proteins followed by CRM-1 dependent nuclear transport (Sneddon et al. 2003). Cofactors which contribute during the synthesis of selenoproteins are SECp43 as tRNA ${ }^{\text {Sec }}$ binding protein and the 


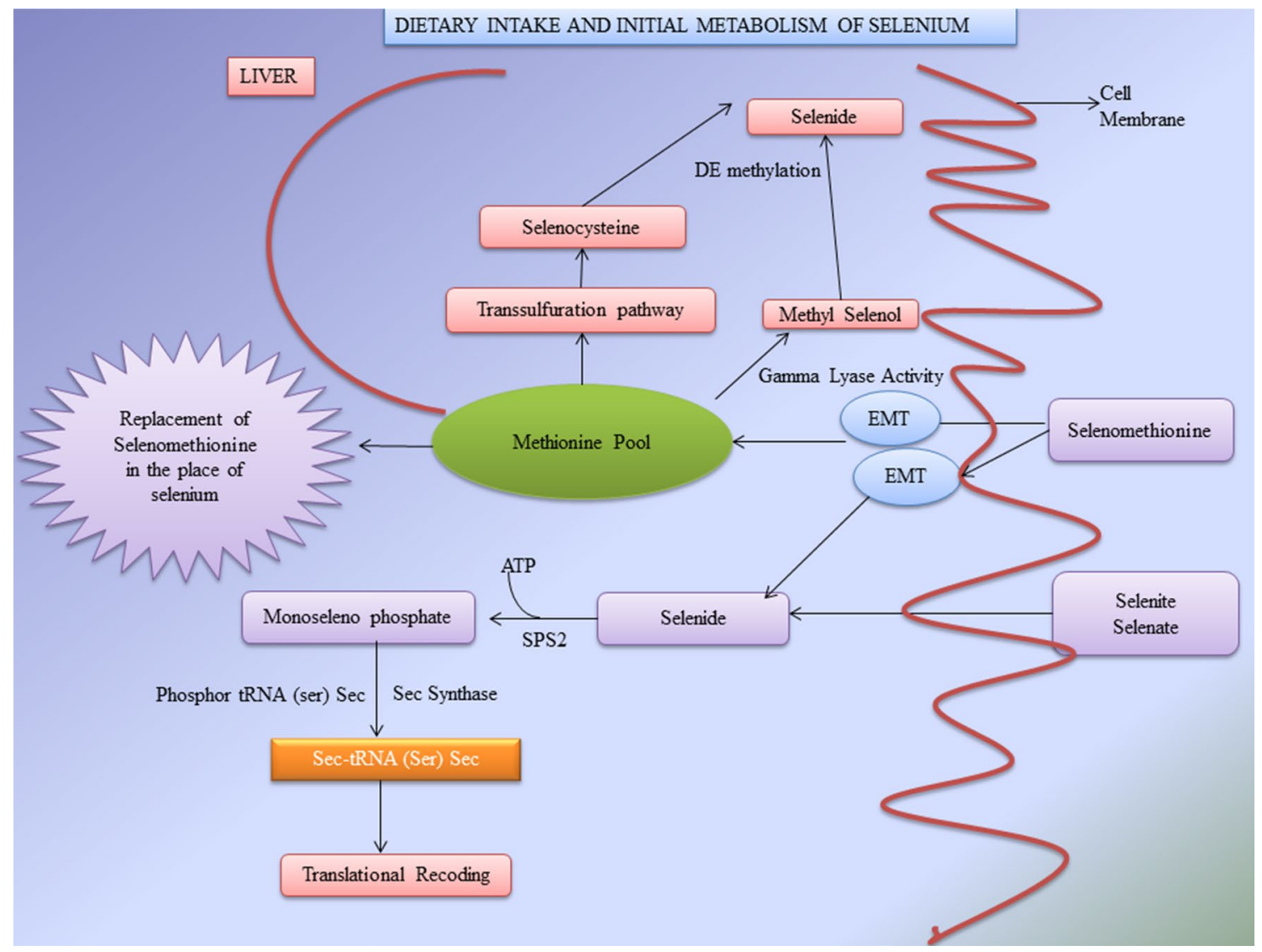

Fig. 2 The dietary intake and initial metabolism of selenium in the human body (SPS2 selenophosphate synthase 2, $t R N A^{\operatorname{Sec}}$ tRNA for selenocysteine, EMT epithelial-to-mesenchymal transition)

chaperone protein which binds to SECIS element and plays a role in protein translation (Shen et al. 2006). Another SECIS element binding protein is said to be nuclease sensitive element-binding protein 1 (NSEP1) which binds during the synthesis of selenoproteins via ribosomal pathway (Allmang et al. 2009). Translational decoding of selenoproteins gives idea on the importance of selenium in human metabolism and health. The selenoproteins synthesis processes such as translational decoding of selenocysteine, locations and their transport are shown in Figs. 3 and 4.

\section{Role of Glutathione peroxidases-a type of selenoprotein in wound healing}

When an injury occurs, the platelets start to aggregate and form thrombi at the wounded area. Meanwhile, the immune cells release the pro-inflammatory cytokines and neutrophils which produce huge amounts of reactive oxidative species (ROS) like hydrogen peroxidases (HP) and lipid peroxidases (LP). Reactive oxygen species (ROS) are the substances that are formed as a natural byproduct and have important roles in cell signalling and homeostasis. However, during times of environmental stress (e.g., UV or heat exposure), ROS levels can increase dramatically which may result in significant damage to cell structures and cumulatively-this is known as oxidative stress. During inflammation, Matrix Metaprotease (MMP), HP, metal scavengers and LP are released, resulting in higher expression levels of NOX2 gene in plasma membrane of cells and NOX2 gets activated during phagocytosis leading to production of superoxide radicals (Sen and Roy 2008; Gill and Parks 2008).

Glutathione peroxidases (GPXs) of selenoprotein family play a major role in the wound healing process. Glutathione peroxidases (GPXs) are known as the family of antioxidants. There are eight types of GPXs with diverse characteristics and properties such as chemical forms, location, functions and modes of action (Brigelius-Flohe and Maiorino 2013). Out of eight isoforms of GPXs, five have a SeCys residue in their side chains which helps to catalyse the hydrogen peroxidases, lipid peroxidases and heavy metals. Glutathione (GSH) reduces disulphide bonds formed within cytoplasmic proteins to cysteine by serving as an electron donor. In the process, glutathione is converted to its oxidised form, glutathione disulfide (GSSG), also called L-(-)-glutathione (Takeda 2015). GPXs detoxify the hydrogen peroxide into 


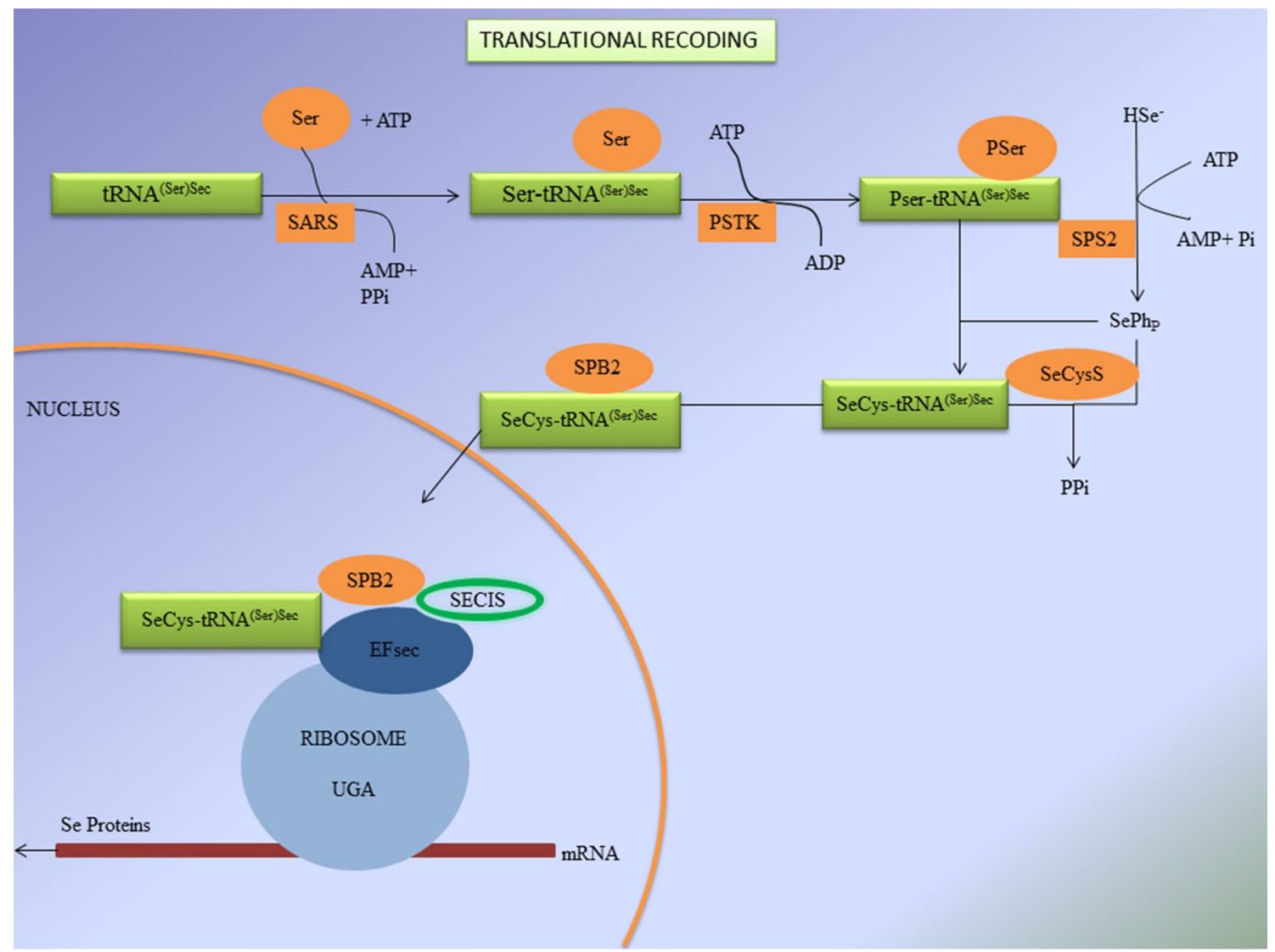

Fig. 3 Biosynthesis of selenoproteins/translational decoding $\left(t R N A^{S e c}\right.$ tRNA for selenocysteine, SARS Seryl-tRNA sythetase, PSTK phosphoseryl-tRNA kinase, PSer phosphoserine, SPS2 selenophosphate synthase 2, SeCysS selenocysteine synthase, SeCys selenocysteine,

peroxidases to avoid Fenton's reaction or Haber-Weiss reaction (several metals have a special oxygen transfer property which improve the use of hydrogen peroxide and some metals have a strong catalytic power to generate highly reactive hydroxyl radicals). It has been observed that during inflammatory process a strong mRNA expression of GPX was found which helps in the wound healing (Bedard and Krause 2007; Steiling et al. 1999). Later researchers state

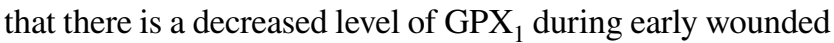
phase resulting in the reduction of its activity in wounded control and immune-compromised rats (Iuchi et al. 2010). It has been reported that alkylation or nitric oxide dependent oxidation of selenocysteine results in reduction of GPXs activity (Gupta et al. 2002). Excess of hydrogen peroxide and super oxide dismutase (SOD) causes the selenocysteine to get converted into dehydrolalanine, which results in irreversible inactivation and degradation (You et al. 2010). The study clearly revealed that the protein levels of GPX1 are increased between 3 and 7 days after skin injury (Woo et al. 2010). Availability of selenium restricts the abundance of GPX proteins. Trauma patients with skin wound healing
$S B P 2$ selenocysteine incorporation sequence binding protein 2, $S E C I S$ selenocysteine insertion sequence, EFsec specialized elongation factor, $\mathrm{HS}^{-}$hydrogen selenide)

disorder present with reduced serum selenium status. Therefore, lower selenium restricts the abundance of GPX2 protein; providing patients with selenium supplementation helps to improve GPX2 protein level (Blass et al. 2013). Appropriate mechanism responsible for this needs to be further experimented. Selenium can be used as therapeutic agents for the treatment of wound healing disorders. The functions of various selenoproteins during the wound healing process are shown in Fig. 5.

\section{Role of selenoprotein S in wound healing}

During inflammatory phase in wound healing process, soluble factors such as chemokines and cytokines are released, which can phagocytise the debris, bacteria, and damaged tissues. Recent studies suggested that selenoprotein $\mathrm{S}$ is plays a crucial role in inflammatory phase. Selenoprotein $\mathrm{S}$ (otherwise named as Sel S, SELENOS, TANIS, SEPS1 and VIMP) is a transmembrane protein found in Endoplasmic Reticulum (ER) and plasma membranes. Their major 


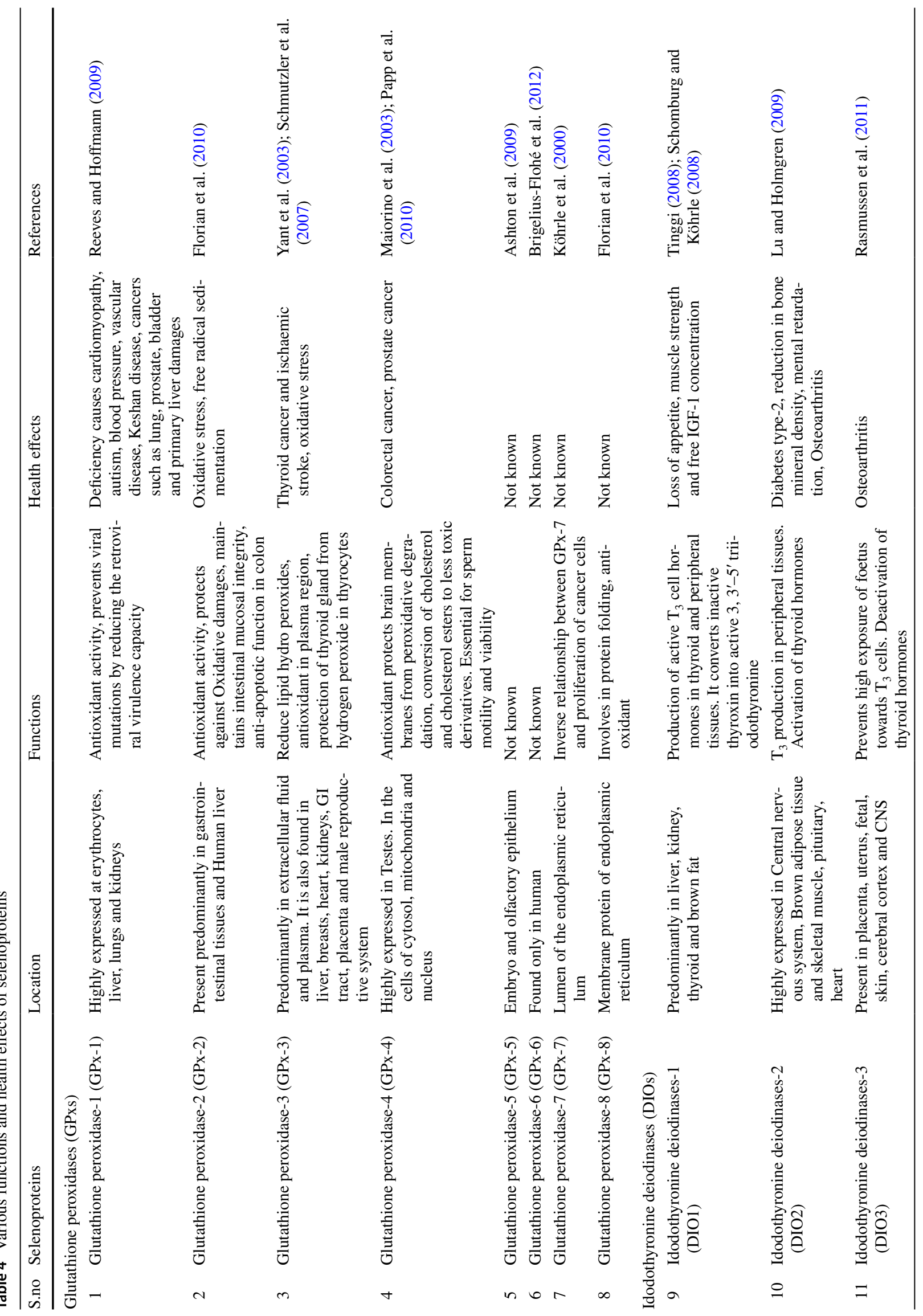




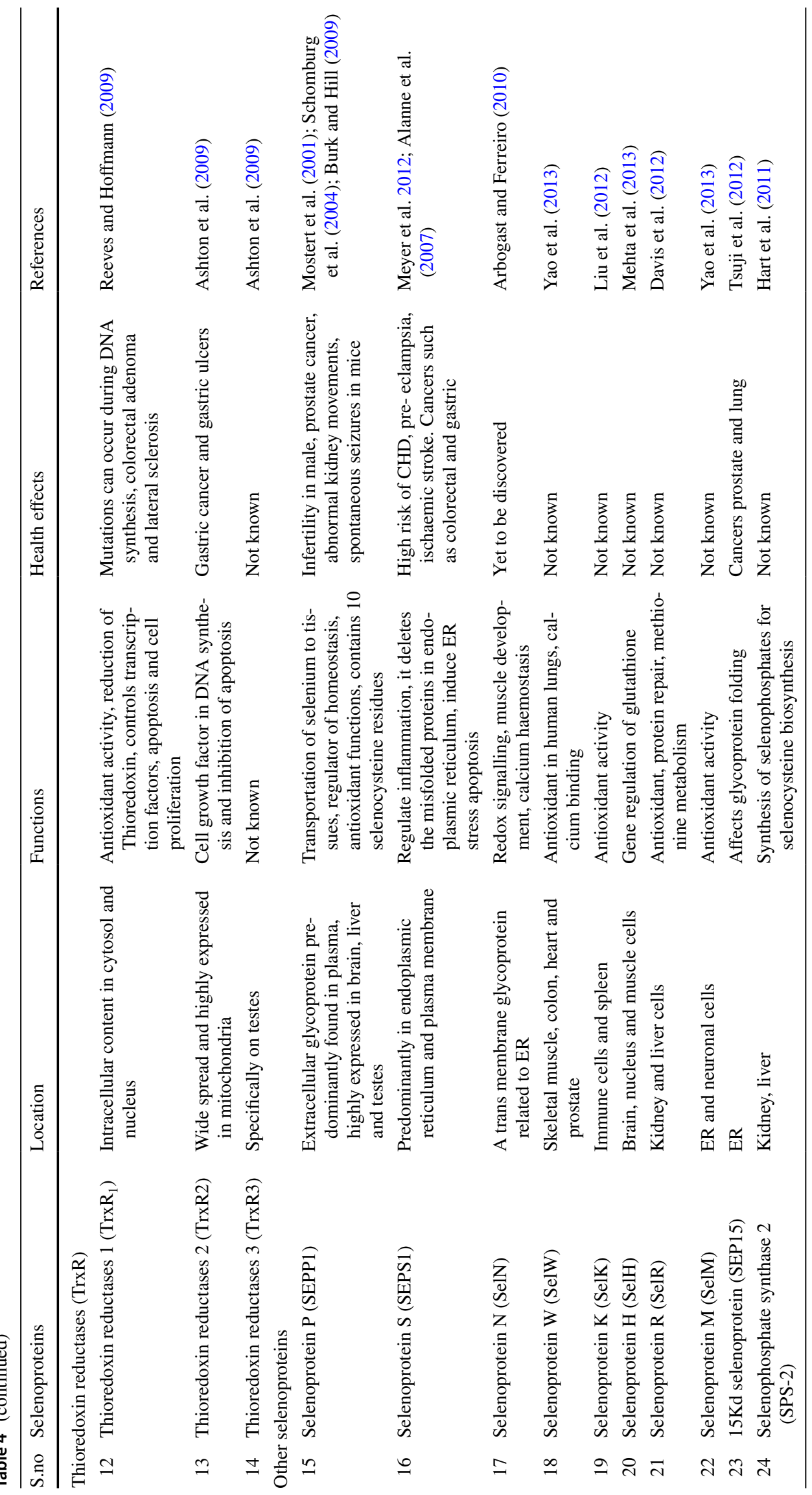




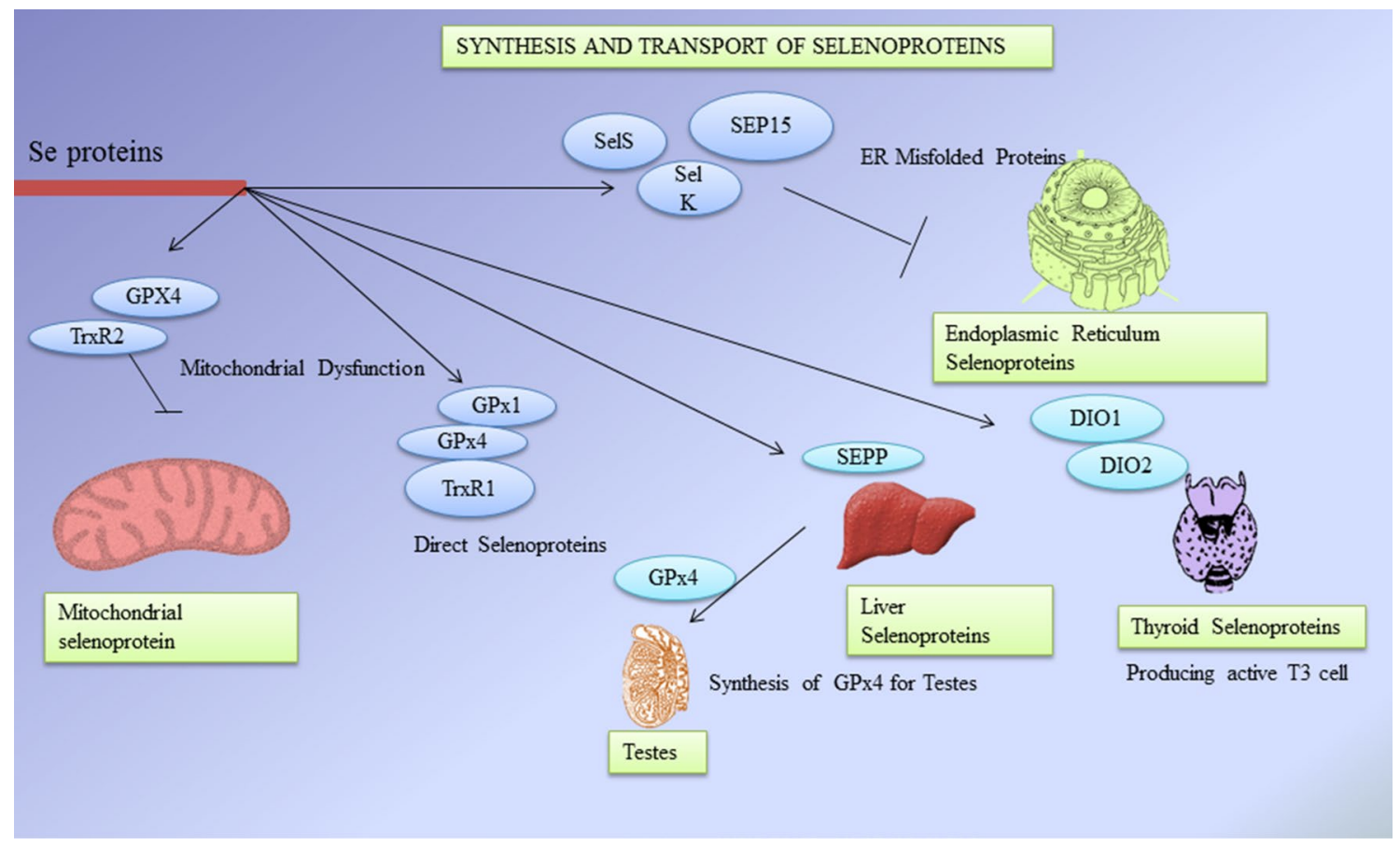

Fig. 4 Synthesis and transport of selenoproteins (GPX Glutathione peroxidases, TRXR thioredoxin reductases, SEPP selenoprotein P, SEP15 15kDa selenoprotein, SelK selenoprotein K, SelS selenoprotein S, DIOs iodothyronine deiodinases, T3 3,5,3'-triiodothyronine)

activity includes (1) removing the misfolded proteins from ER lumen (2) protecting the cells from oxidative damage and (3) participating in ER-stress induced apoptosis. Selenoprotein $\mathrm{S}$ was initially derived from diabetic rats during the observational studies on fasting diabetic assay (Walder et al. 2002; Ye et al. 2004; Gao et al. 2004, 2007). This study also reveals that Sel S interacts with Serum Amyloid A (SAA), an acute phase inflammatory response protein and provides a mechanistic link between Type- 2 diabetes, inflammation and cardio vascular disorders. Other reports state that Endoplasmic Reticulum stress induces the Sel S expression by ER stress response element via nuclear factor (NF)-kb pathway (Gao et al. 2006). The depletion of Sel S by siRNA increases the release of inflammatory cytokines IL- 6 and TNF- $\alpha$, concluding that Sel S may regulate the cytokine production in macrophages and plays a major role in controlling the inflammatory responses. A particular polymorphism of Sel $\mathrm{S}$ was proven to be responsible for increased plasma levels of the inflammatory cytokines. Sel S gene has been linked to variant markers of inflammation and one among the particular variant is 105G-A (Curran et al. 2005). The role of Sel S in the inflammatory response may be correlated with the inflammation phase of the wound healing mechanism. But still these assumptions can be solved in future with more experimental evidences. The assumptions are shown in Fig. 5.

\section{Role of other selenoproteins in wound healing}

\section{Thioredoxin reductases}

There are three Thioredoxin Reductases (TR1, TR2, and TR3). The major functions of TRs are to control the redox signalling and antioxidant activities (Ducros and Favier 2004). Thioredoxin system plays an important role in the regulation of gene expression via redox control of transcription factors including NF-kB, Ref-1, AP-1, P-53, Glucocorticoid receptor and apoptosis regulating kinase (ASK-1) which results in immune responses and other major activities (Selenius et al. 2010). They have the ability to reduce the ascorbyl free radicals through recycling the ascorbate. Humans lack the capacity to synthesise ascorbic acid which is an important antioxidant in the protection of cells from oxidative stress and inflammatory responses (Mustacich and Powis 2000). Thus, the selenoprotein derivative such as Thioredoxin reductase plays important role during oxidative stress and inflammation in wound healing process.

\section{Selenoprotein P}

Selenoprotein P (SEPP 1, Sel P) is the only selenoprotein which contains 10 selenocysteine residues (Olson et al. 2005). It is a glycosylated protein where there are 3 


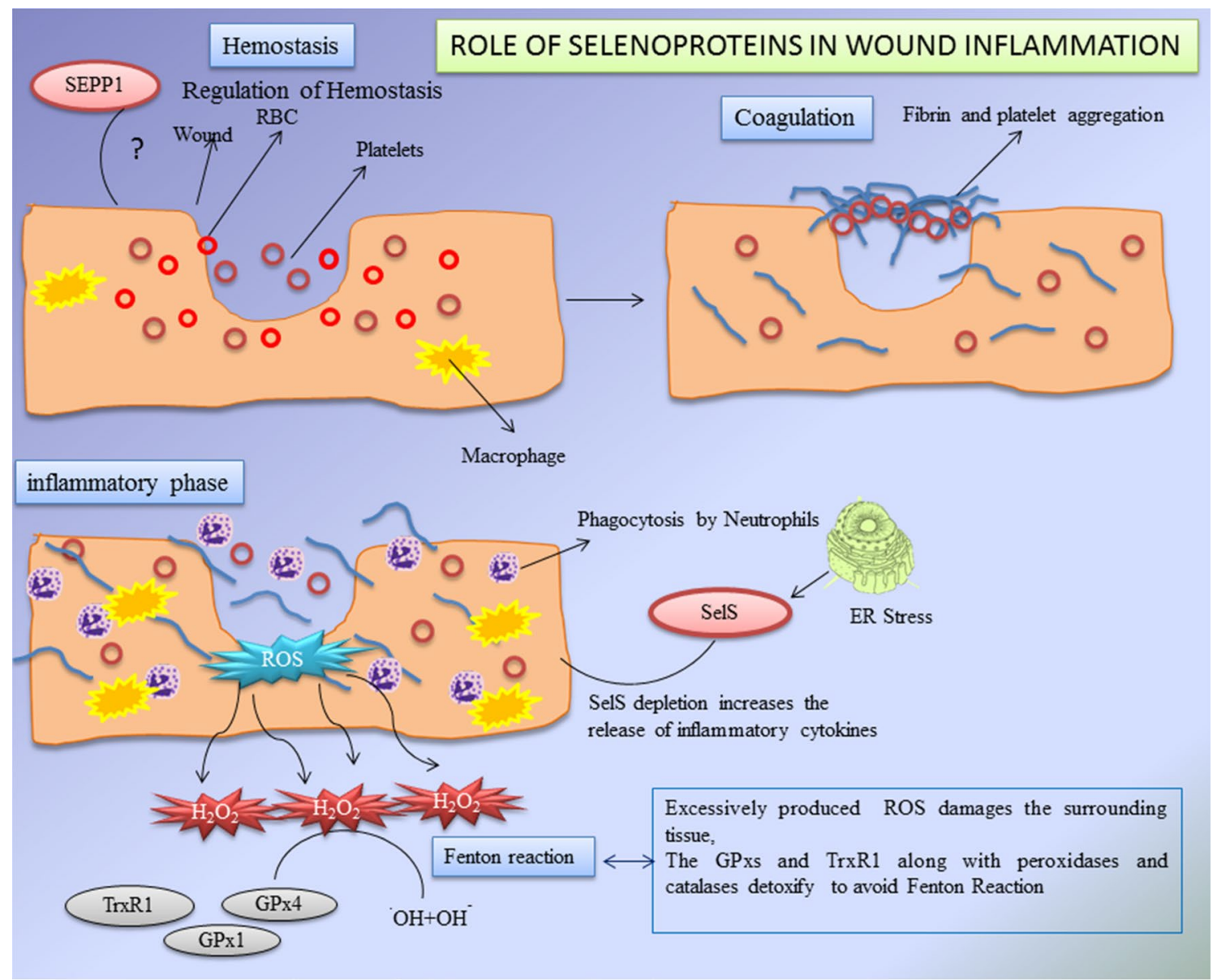

Fig. 5 Role of selenoproteins (GPXs, TrxRs, Sel P and Sel S) during wound healing process (GPXs GPX-Glutathione peroxidases, TrxRs thioredoxin reductases, SelK selenoprotein $\mathrm{K}$, SelS selenoprotein $S$ )

occupied $N$-glycosylation site and 1 occupied $O$-glycosylation site (Suzuki et al. 2010a, b). Sel P is mainly produced in liver and then transported to plasma. Sel $\mathrm{P}$ is released into the blood stream and is responsible for the distribution of selenium to other organs and tissues (Burk and Hill 2005). With these evidences we assume that selenoprotein $\mathrm{P}$ acts as a selenium transport system and also selenoprotein $\mathrm{P}$ is responsible for maintaining the haemostasis throughout the human body during the normal and disturbed metabolism (e.g. during wound healing process) (Schomburg et al. 2003). Focusing on the relationship between selenoprotein $\mathrm{P}$ and wound healing mechanism requires further studies.

\section{Selenium drugs}

Selenium is an important micronutrient for the human body that is especially received via food supplement (Lau et al. 2017). Very small amounts of selenium are required for maintance of ideal health as selenium is a constituent of the selenoproteins that contribute to a vast array of cellular functional processes (Wu et al. 2015). The functions like redox regulations, immunity and inflammatory reactions, cardiovascular and reproductive well-being, brain activities and repairs, thyroid hormone control factors and carbohydrate regulations too (Forootanfar et al.2014; Mistry et al. 2012). Selenium deficiency is related to several human illnesses with numerous levels of diseases (Vinceti et al. 2017). Excessive selenium intake can be toxic and might lead to selenosis condition (Sutter et al. 2008). Currently, the recommended dietary allowance of selenium for adults is set at $55 \mu \mathrm{g}(0.7 \mu \mathrm{mol}) / \mathrm{day}$. Individuals with day by day selenium intake much less than $\sim 15 \mu \mathrm{g}$ appear to be susceptible to selenium deficiency-associated illnesses, while folks who consume over $400 \mu \mathrm{g} /$ day are prone to selenium toxicity, although a few researches have proven that safe ranges of selenium intake may be a whole lot decrease than anticipated (Vinceti et al. 2001). 


\section{Selenium containing compounds for cancer treatment}

The relationship between selenium and cancer was explored during the middle of the nineteenth century, which then outstretched the interest in selenium supplements to cancer prevention and therapy. The selenium containing compounds can be grouped into three main types (1) inorganic, (2) organic (natural and synthetic) and selenium nanoparticles (SeNPs) (recently added) which has exhibited anticancer ability.

Generally it is shown that selenium compounds exhibit anticancer capability primarily through their direct or indirect antioxidant properties that sustain the intracellular redox status and these actions guards the healthy cells from reactive oxygen species induced oxidative damage (Rahmanto and Davies 2012). Reactive oxygen species are free radicals generated during normal bio-physiological functions with unpaired electrons and there is evidence that excessive reactive oxygen species promotes carcinogenesis via raised oxidative stress and DNA mutation (Prasad et al. 2017). Despite the links between reactive oxygen species and cancer formation but still ideal (usually low) levels of reactive oxygen species are actually helpful as they play important roles in regulating many biological functions. Some enzymes and cells intentionally produce superoxide radicals to destroy the attacking pathogens (Georgieva et al. 2017). Reactive oxygen species also terminate the damaged cells by stimulating cellular senescence and apoptosis (Valko et al. 2006).

Research on inorganic and organic forms of selenium compounds have metabolized differently and have diverse mechanisms of action towards cancer cells. Organic selenium compounds are better retained and utilised than inorganic forms though the both are readily absorbed in the human body (Fairweather-Tai et al. 2010). Numerous publications with biochemical, epidemiological, clinical, and animal studies supports the cancer prevention ability of inorganic and organic selenium compounds (Rayman 2005; Papp et al. 2007; Jackson and Combs 2008; Hatfield et al. 2009; Fernandes and Gandin 2015; Brigelius-Flohé and Flohé 2017). Conversely, selenium compounds toxicity risks have also been recorded. It has been found that inorganic selenium compounds shows higher genotoxic stress, which may have lower therapeutic value, higher toxicity and an increased threat on cancer proliferation. Contrarily, organic selenium compounds retain significant anti-tumor activity along with increased ability to prevent metastasis, have fewer side effects and lower systemic effects. Organic selenium compounds comprise a vast group of chemically diverse nucleophilic molecules. In reality, the toxic effects of selenium compounds are determined by multiple factors, its forms and dosage exposure being two of the most important parameters (Misra et al. 2015).

\section{Inorganic selenium compounds}

Commonly studied inorganic selenium compounds include the sodium selenite and sodium selenate for the cancer prevention and treatment. Depending on their valence states of these compounds, the functions and its effects differ. Different concentrations of sodium selenate $(5,10,30,50 \mu \mathrm{M}$ for $48 \mathrm{~h})$ and sodium selenite $(0.1,0.25,0.5 \mu \mathrm{M}$ for $48 \mathrm{~h})$ were tested for their capability to sensitize human oral squamous carcinoma (KB) cells which were resistant to chemotherapeutic drug vincristine (KBV20C). On observation they found that they are able to sensitize KBV20C to the similar level as the sensitive parent KB cells. By arresting the cell cycle at G2-phase and activating apoptotic pathways, Sodium selenite compound are able to show higher sensitizing effect on the KBV20C cells (Choi et al. 2015).

The most studied inorganic selenium compounds are sodium selenite which exhibits outstanding chemo-preventive and anticancer features (Kieliszek et al. 2017). The compound produced noticeable anti-proliferative activities against three oral cancer cell lines (HSC-3, HSC-4, and SAS) at a concentration of $5-100 \mu \mathrm{M}$ on treatment for 2-5 days (Endo et al. 2017). Sodium selenite was found to be efficiently inhibiting the cell proliferation of several types of cancer cells even the deadliest cancer in worldwide, the lung cancer cells too (Tan et al. 2018). Among different human cancer cell lines tested, lung cancer cells, in general, appeared to be especially sensitive to selenite (Berthier et al. 2017; Lipinski 2017; Chen et al. 2018a, b). Previous reports showed that selenite cytotoxicity at concentration of $5 \mu \mathrm{M}$ for treatment of $5 \mathrm{~h}$ was correlated with selenium uptake of three lung cancer cell lines (H157, H611, and U2020) and it results indicated that at high concentrations $(>1 \mathrm{mM})$ of selenate was found to be non-toxic for these cell lines (Olm et al. 2009). Selenite played a key role in natural killer (NK) cell-based anticancer immunotherapy where it could raise the susceptibility of cancer cells to CD94/NK group 2A-positive NK cells, and it showed positive clinical applications to lung cancer patients (Enqvist et al. 2011). On reduction of sodium selenite to hydrogen selenide which is the common intermediate of dietary selenium metabolism might activate the apoptosis of cancer cells (HepG2, HeLa, and MCF-7 cells) through accumulation in mitochondria, this might then damage mitochondrial function and structure which lead to cell death (Hu et al. 2018). In general most of the inorganic selenium compounds exhibit higher genotoxic stress, which account for lower therapeutic value, higher systemic toxicity and an increased risk of tumour burden.

\section{Organic selenium compounds}

In the field of cancer research organic selenium compounds drew more attention than inorganic selenium compounds 
because of their lesser toxicity risk and have capability to bring substantial anticancer activity (Ronaiet al. 1995; Jariwalla et al. 2009). Some of the organic selenium compounds like selenoaminoacid derivatives (selenomethionine, selenocystine, Methylseleno-cysteine, selenodiglutathione), Methylseleninic acid, Ebselen, Ethaselen, Diselenides, selenazofurin, selenocyantes, selenoesters, selenium-nonsteroidal anti-inflammatory drug (Se-NSAID), selenoureas, selenocarbonyl derivatives are explained below with their functions and structures in Table 5 (Gandin et al. 2018). These compounds display anticancer and chemo-preventive activity by their different mechanisms of action like reducing the oxidative stress, inducing apoptotic events and enhancing the chemotherapeutic activity. Organic selenium compounds have all capabilities to be used as anti-neoplastic agents against solid tumours (Álvarez-Pérez et al. 2018). Organic selenium compounds largely preferred in cancer therapy because of its anti-necrotic and pro-apoptotic features since necrosis in cancer cells is related to host inflammatory response and may lead to treatment complications (Ali et al. 2018).

\section{Natural organo-selenium compounds}

Selenomethionine Selenomethionine has displayed prominent cytotoxicity in many cancer cells like lung, breast, colorectal, prostate, melanoma and this was achieved at higher concentrations from medium to high $\mu$ molar. Selenomethionine induced apoptosis by numerous pathways like the activation of caspases, p53, ER stress, HDAC inhibition, altered expression of Bclxl, Bax, Bad and Bim, decreased cyclooxygenase-2 expression and decreased glutathione peroxidase activity (Baines et al. 2002; Yang et al. 2009). Furthermore, selenomethionine on combination with ionizing radiation exhibited enhanced selectivity towards NCIH460 and H1299 lung cancer cells, whereas having slight effect on WI-38 human diploid lung fibroblasts (Shin et al. 2007). Reports on low systemic toxicity and high tumor selectivity of selenomethionine compound in a mouse xenograft model of colorectal carcinoma (SW480) (Suzuki et al. 2010a, b).

Selenocystine It is a diselenide oxidation product formed from the amino acid selenocysteine. By low-molecular weight thiols and disulphide reductases this selenocystine being efficiently reduced to selenocysteine which is of highly redox active in nature. Their cytotoxic effects were found to be in the low to medium $\mu \mathrm{m}$ range for lung, breast, cervical, liver cancer cells and also in melanoma cells. Cytotoxicity of selenocystine is due to increased ROS production which induces DNA damage and leads to mitochondrial mediated apoptosis associated with p53 phosphorylation. In addition to these cytotoxic mechanisms selenocystine exhibited the extrinsic/death-receptor pathway in melanoma cells (Chen and Wong 2008). In another study selenocystine treatment in cervical cancer cells has been related with two different types of cell death via apoptotic and paraptotic-like associated with ER stress which leads to induction of the unfolded protein response (UPR) (Wallenberg et al. 2014). Selenocystine inhibited tumor growth in a mouse xenograft model of melanoma with no signs of systemic toxicity. Further, selenocystine and auranofin exhibited a synergistic effect on inducing apoptosis in a mouse xenograft model of lung cancer (Fan et al. 2014). Selenocystine on administration in humans for acute and chronic myeloid leukemia treatment worked remarkably, particularly effective against immature leucocytes with respect to mature leucocytes and also without bringing any significant effect on the bone marrow (Weisberger and Suhrland 1956).

Methylselenocysteine It is derivative of mono-methylated selenoaminoacid which is converted to methylselenol by activity of selenocysteine Se-conjugated $\beta$-lyases (Suzukiet al. 2007). Methylselenocysteine efficacy is completely dependent upon the production of the active metabolite, methylselenol which varies across cells, tissues and organs. The in vitro cytotoxicity of this compound has been found out to be in micromolar $(\mu \mathrm{m})$ range for many human cancer cell lines which includes colon, breast, lung and oral squamous cells. Furthermore, Methylselenocysteine treatment in in vitro has also shown to decrease vascular endothelial growth factor expression (Suzuki et al. 2010a, b). Moreover, the mechanisms by which Methylselenocysteine treatment causing cell death has been associated with role for caspasedependent pathway and to extent of mitochondrial signalling involvement in this process still remains unclear (Kim et al. 2001; Suzuki et al. 2008; Schröterová et al. 2009). Methylselenocysteine treatment in mice bearing FaDu human head and neck squamous cell carcinoma xenografts has caused series of promising antiangiogenic effects, tumor growth inhibition, enhanced doxorubicin delivery associated with decreased microvessel density, improved vascular maturation, better vessel functionality and decreased vascular permeability (Bhattacharya et al. 2008). Similarly, a synergistic effect on tumor growth inhibition by Methylselenocysteine and tamoxifen was detected in a mouse xenograft model of MCF-7 breast cancer (Li et al. 2009). In another study a similar synergistic effect of Methylselenocysteine and irinotecan was witnessed in mouse xenograft models of colon carcinoma and squamous cell carcinoma of the head and neck. Likewise this chemotherapeutic synergy effects was also apparent in both sensitive (HCT- 8 and $\mathrm{FaDu}$ ) and drugresistant (HT-29 and A253) xenografts (Cao et al. 2004).

Selenodiglutathione During the reduction of selenite by glutathione, the selenodiglutathione metabolite is formed. 


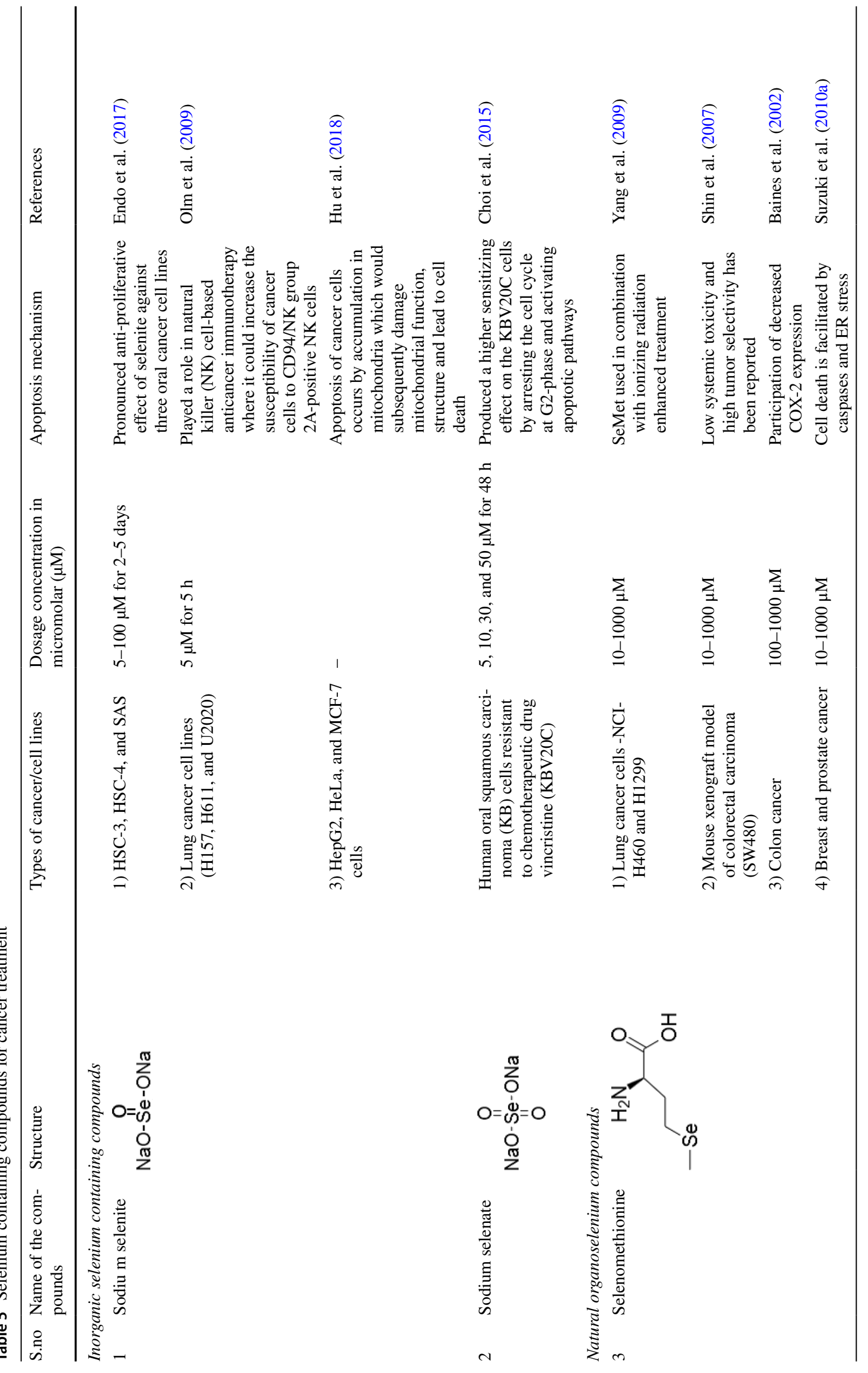




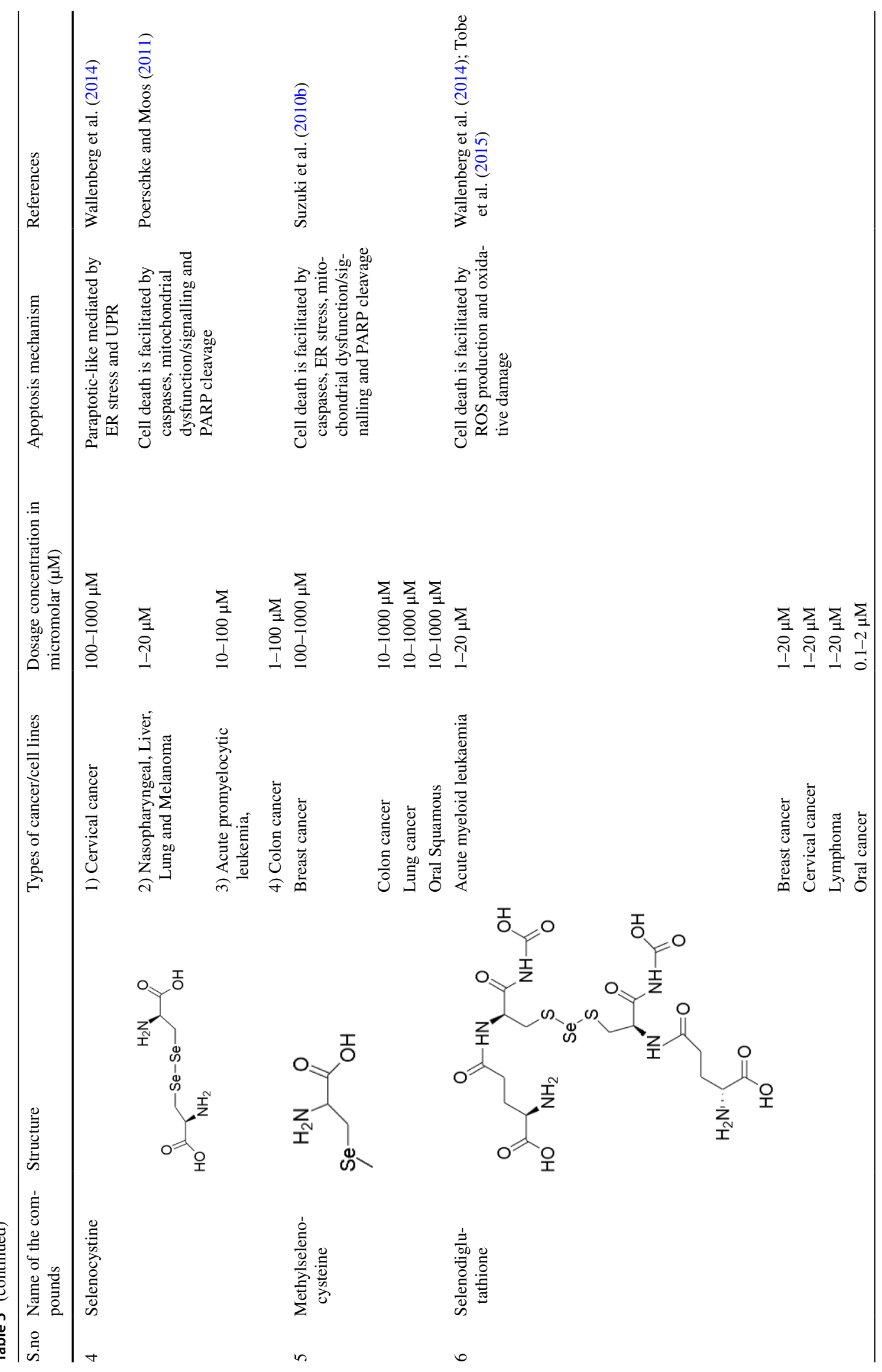




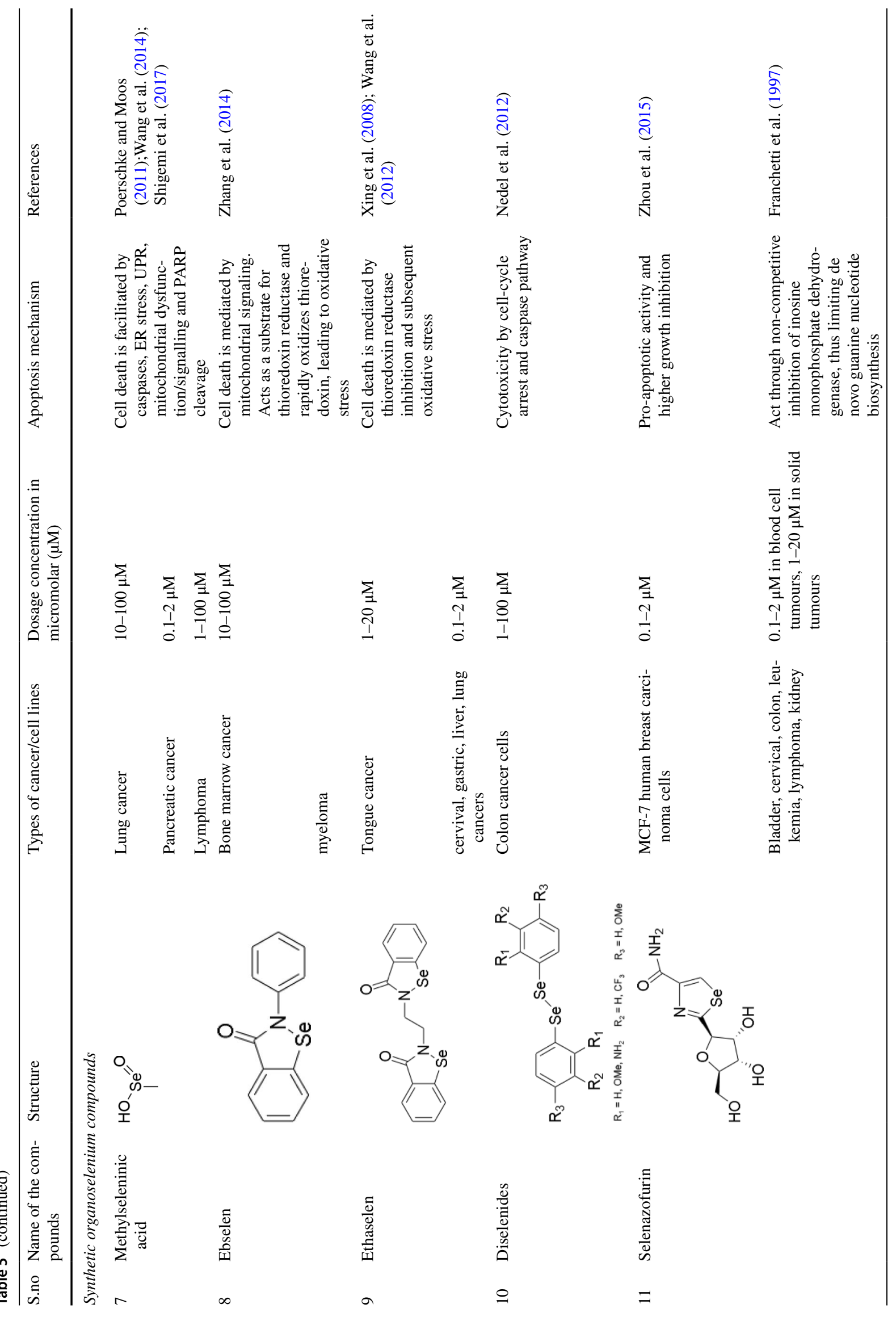




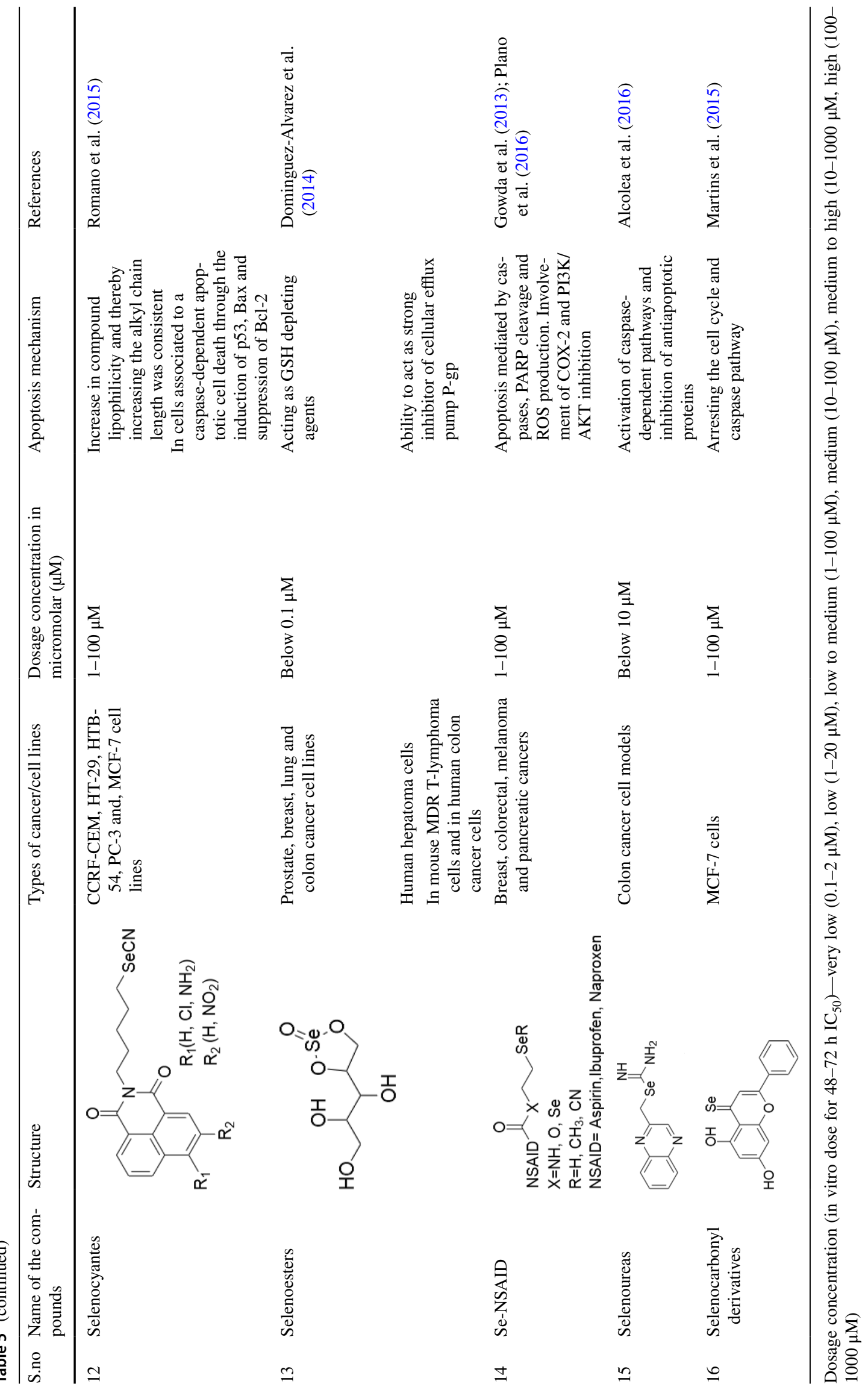


Through glutaredoxin and thioredoxin systems activity, selenodiglutathione is reduced to hydrogen selenide by glutathione. This pro-oxidant play a central role in redox cycling with glutathione and producing superoxides, hydrogen peroxide which further results in ROS generation (Björnstedt et al. 1992; Wallenberg et al. 2010). Selenodiglutathione showed apoptotic effect in the low $\mu \mathrm{m}$ concentrations towards different cancer cells like breast, ovarian, cervical, lymphoma, promyelotic leukemia and oral squamous (Wu et al. 1995; Last et al. 2006; Tobe et al. 2015). Recently it has also been shown that selenodiglutathione exhibited different intracellular targets, expression patterns and mechanism of cytotoxicity when compared to selenite treatment (Wallenberg et al. 2014).

\section{Synthetic organoselenium compounds}

Till the year 1990, the chemistry of organoselenium compounds was hardly established in contrast with that of organosulfur compounds, mainly because of the high uncertainty and harmfulness of numerous Se-containing compounds. But lately due to developments in the field of synthesis and reactivity of organoselenium compounds as well as the discovery on the essential role of selenium and selenoproteins in cancer has enormously motivated for the intense development of new therapeutics in medicine.

\section{Methylseleninic acid}

The compound was synthesized on oxidative decomposition of methylselenocysteine and it is most simple organic selenium compounds with therapeutic properties. They are able to kill cancer cells in different cell lines through the activation several caspase pathways (3, 7, 8 and 9), ER stress, UPR induction, cytochrome c release and PARP cleavage (Jiang et al. 2001, 2002; Singh et al. 2008; Shigemi et al. 2017). They induce apoptosis specifically in p53 wild-type, p53-mutant, p53-null cells and therefore representing a p53-independent cancer cell death pathway ( $\mathrm{Zu}$ et al. 2006). In vivo and in vitro studies have shown that Methylseleninic acid has been excellent anticancer agent against a range of cancer models like lung, breast, melanoma and prostate cancers (Plano et al. 2007). In a recent study, Methylseleninic acid has exhibited substantial cytotoxic effects toward monocytic leukemia cells (THP1) when likened with the healthy peripheral blood mononuclear (PBM) cells. In dose-dependent manner at various concentrations $(2.5,5$, and $15 \mu \mathrm{M}$ for $48 \mathrm{~h}$ ), Methylseleninic acid showed improved anticancer activity against the malignant THP1 cells (Lobb et al. 2018).

\section{Ebselen}

Ebselen [2-phenyl-1,2-benzisoselenazol-3(2H)-one (PZ-51)] was synthesized by Lesser and Weiss in 1924 and measured immaterial pharmacologically for 60 years. Later Helmut Sies gave a new life by highlighting the abilities of this molecule to mimic the activity of glutathione peroxidase enzyme (Muller et al. 1984; Zhao et al. 2002). From that time surplus of studies has been carried out on the pharmacological and biochemical properties of Ebselen (Azad and Tomar 2014). Recent reports on various applications of Ebselen include anticancer, antimalarial antitubercular and neuroprotection agent (Parnham and Sies 2013).

Ebselen is an effective source of thioredoxin reductase, and which stimulates the thioredoxin to get rapid oxidation. Anti-oxidative properties of this compound have been extensively studied, but only few studies on ebselen highlights about the antiproliferative and anticancer properties through ROS production (Zhang et al. 2014). Ebselen might also alter the mitochondrial function by Bax activation and these properties leads to inhibit Quiescin sulfhydryl oxidase 1, an enzyme that helps in promoting the growth and invasion of tumor cells by altering the extracellular matrix composition (Hanavan et al. 2015). There has been report that on daily oral treatment with ebselen has resulted in a 58\% reduction in tumor growth in mice bearing human pancreatic tumor xenografts. Major antitumor proficiency was attained by combining the ebselen with gamma radiation which induces apoptosis and as well helps in modulating the response of pro- and anti-inflamatory cytokines (Thabet and Moustafa 2017).

New cyclo-hexyl ring containing ebselen analogues has been synthesized which showed higher redox properties and also reducing cell growth in both MCF-7 and DU145 cancer cell lines with $\mathrm{IC}_{50}$ values that were within the low micromolar range (Pacula et al. 2017). Sequences of benzoselenazole-stilebene hybrids were synthesized by combining ebselen and reservatrol. These were designed to develop more multi-target redox-active agents. Certainly upon their biological assessments, it showed that all the developed test compounds acted as antiproliferative agents in the human cancer cell lines Bel-7402, A549, HeLa, and MCF-7 and also proven to be TrxRd inhibitors. Furthermore, mechanistic studies indicated that these compounds increase the intracellular ROS which implements apoptosis in cancer cells (Yan et al. 2015).

\section{Ethaselen}

Ethaselen (1,2-[bis(1,2-benzisoselenazolone-3(2H)ketone)]ethane) has been widely studied in a number of cell lines (Zhao et al. 2006) and it is found to target and inhibit the central antioxidant and redox regulatory enzyme, 
thioredoxin reductase, which has been the promising target for any anticancer drugs (Urig and Becker 2006). Ethaselen, through thioredoxin reductase inhibitory effect arrest the cell growth $\mathrm{S}$ phase and thereby the proliferation of tumor cells was inhibited (Shi et al. 2003). Concurrently, ethaselen established promising outcomes in in vivo experiments, with tumor inhibitory effects in the range of $40-80 \%$ in prostate, tongue and liver cancer models (Xing et al. 2008; Tan et al. 2009; Wang et al. 2012). Ethaselen in combination with cisplatin (cis-diamine dichloroplatinum II, DDP) in a lung xenograft mouse model showed significant synergistic reduction of tumor size, with no evident signs of systemic or organ toxicity (Tan et al. 2010). Combination of cisplatin and ethaselen produced similar results in a leukemic cisplatin resistant cell line with substantial synergistic effects. Ethaselen with Sunitinib (multitargeted tyrosine kinase inhibitor) combination has exhibited similar synergistic effects against spreading of colorectal cancer cells (Zheng et al. 2016). In spite of ethaselen encouraging anticancer activity, its solubility in physiological media is not ideal, thus preventing its application without appropriate formulation. Copolymer micelles have helped in increasing ethaselen water solubility which led to enhanced antitumor activity and attribute to massive accumulation at the tumor site (Liu et al. 2010). Currently ethaselen is in Phase I clinical trials in patients with non-small cell carcinoma (NSLCLC). Tolerable and safe dose in the Ia/b phase was found to be $1200 \mathrm{mg} /$ day (ClinicalTrials.gov identifier: NCT02166242).

\section{Diselenides}

Diselenides are characterized by the presence of a $\mathrm{Se}-\mathrm{Se}$ bond largely used in organic synthesis because of their accessibility through a number of different synthetic protocols and relative stability. Diphenyldiselenide exhibited substantial cytotoxicity against neuroblastoma cells and it is effectively carried out through ERK1/2 mediated apoptosis (Posser et al. 2011). Substituted diaryldiselenides (3-(trifluoromethyl)-diphenyldiselenide and 4-methoxydiphenyl diselenide) have capability to induce cytotoxicity by cell-cycle arrest in human colon cancer cells and triggering the caspase-dependent or independent pathways (Nedel et al. 2012). Diphenyldiselenide can perform as a substrate for thioredoxin reductase which gives foundation for the progress the novel diselenides as prospective anticancer agents (De Freitas and Rocha 2011). Later diverse sequence of diselenides containing bioactive ligands (e.g., naphthalene, cyclic imides) or medically relevant heterocycles (e.g., thiazolidinone, tetrazole, pyrazole and thiazolopyrimidine) are developed and few showed cytotoxicity at sub-micromolar concentrations against many cancer cell types (Shaaban et al. 2015; Abbas et al. 2015). These compounds induce cytotoxicity by down regulation of Bcl-2, Ki-67 expression level and also by activated caspase-8 (Shaaban et al. 2016).

\section{Selenazofurin}

Selenazoles are characterized by five-membered rings with the presence of selenium and one methylene group replaced by nitrogen. Selenazofurin are the most studied compound belonging to this class of molecules. In 1983 selenazofurin (2- $\beta$-D-ribofuranosylselenazole-4-carboxamide) was synthesized, which is the Se analog of tiazofurin (Srivastava and Robins 1983). It was shown initially that this compound possesses a noticeable antitumor activity against murine melanoma cancers in in vitro and animal models. It is also likely to exhibit anticancer activity against human promyelocytic leukemia cells in vitro at nanomolar levels (Lucas et al. 1983; Boritzki et al. 1985). Later there are reports on selenazofurin dinucleotides analogues which are found to be more effective than the mononucleotide precursor (Gebeyehu et al. 1985). A new analog called selenophenfurin was developed by replacing selenazole ring with selenophene heterocycle. They are found to be effective against leukemia, lymphoma, and solid tumor cell lines at concentrations alike that of selenazofurin (Franchetti et al. 1997). Selenazofurin as well as its derivatives get metabolized to the selenazole-4-carboxamide-adenine dinucleotides which can perform as effective non-competitive inhibitors of de novo guanine nucleotide biosynthesis like.inosine monophosphate dehydrogenase (IMPD) a rate-limiting enzyme.

\section{Selenocyantes}

Selenocyanates have established their efficacy in the prevention and treatment of variety of cancers both in vitro and in vivo. In specific, phenylalkyl selenocyanates revealed to be effective in in vitro conditions for various cancer cell lines like melanoma, glioblastoma, sarcoma, prostate, breast, and colon. The same compound in in vivo condition was capable of reducing the tumour growth significantly in a melanoma xenograft model, without causing any systemic toxicity or affecting the blood related parameters. The compound was able to affect cancer cell redox state by assessing its cycle in the presence of GSH forming nitric oxide, superoxide and other ROS (Crampsie et al. 2012). There are reports additionally that they effects specific phase II detoxifying and antioxidant enzymes like glutathione- $S$-transferase, superoxide dismutase and catalase and also selenoenzymes like thioredoxin reductase and glutathione peroxidase (Das et al. 2013). These mechanistic conditions in cells lead to caspase-dependent apoptotic cell death via induction of $\mathrm{p} 53$, Bax and suppression of Bcl-2 (Chakraborty et al. 2015). The compound 2-[5-selenocyanato-pentyl]-7-amino benzo[de] isoquinoline-1,3-dione which is the combined form of 
diphenyl-methylselenocyanate and naphthalimide were found to possess effective therapeutic efficacy than the classical chemotherapeutic drugs like cisplatin and cyclophosphamide. Report on the adverse and toxicity effect exhibited by the classical chemotherapeutic drugs has been reduced by this compound (Ghosh et al. 2015). The synthetic compound 1,4-phenylenebis (methylene) selenocyanate (p-XSC) has been found to be effective in in vitro even at low micromolar concentrations against androgen responsive and androgen unresponsive human prostate cancers. They does the activity by inducing cell cycle arrest in the G1 phase, stimulating JNK, p38, ERKs $1 \& 2$ and Akt cancer cell signalling and preventing the m-TOR downstream effectors (Facompre et al. 2012).

A series of selenocyanate derivatives was developed by combining an indole-heterocycle microtubule inhibitor with a selenocyanate moiety. They found to be very promising in vitro antitumor activity even in low $\mu \mathrm{M}$ concentrations against colon, breast and lung cancers and against melanoma. They do this apoptotic activity through mechanism encompassing both microtubule and Akt inhibition (Krishnegowda et al. 2011). A compound selenocyanate containing triterpenes based on homobetulin scaffold was developed and showed antiproliferative activity in the low $\mu \mathrm{M}$ range against non-tumor cells (Sidoryk et al. 2016).

\section{Selenoesters}

Primarily the selenoesters were synthesized on the reason that they can be subjected to hydrolysis or enzymatic reduction in cells which leads to the generation of redox active compounds. These compounds could be readily helps in triggering apoptosis. Many alkyl and aryl selenoesters exhibited readily noticeable cytotoxic activity even in nano-molar concentrations against prostate, breast, lung and colon cancer cell lines (Dominguez-Alvarez et al. 2014).

Among sugar containing selenoesters, xylitol and sucrose based selenious ester have been produced. The xylitolseleno ester has revealed apoptotic conditions in human hepatoma cells in a dose-dependent manner by substituting GSH depleting agents (Guo et al. 2013a, b; Wu et al. 2016). Unfortunately this cytostatic effect was not detected in normal human hepatic cells. Likewise, the sucrose-seleno ester was able to inhibit the propagation of many cancer cell lines in a dose-dependent manner without affecting the normal human liver cells. Further sucrose-seleno ester showed acute toxicity in mice with very high median lethal dose compared to sodium selenite (290.0 and $13.1 \mathrm{ppm}$, respectively). This paves the way for a further preclinical development of this type of selenocompounds (Guo et al. 2013a, b).
Selenium-nonsteroidal anti-inflammatory drug (Se-NSAID)

A nonsteroidal anti-inflammatory drug (NSAID) namely sulindac on combination with selenium compound have inhibited intestinal tumours. They reduced the tumours by $52 \%$ and tumour multiplicities of $80 \%$. Mainly this happened due to expression of p27 and p53 as well as JNK1 phosphorylation (Bi et al. 2013). In another study Se-containing selenocoxib derivative was established. They have the capability to decrease the cell count in melanoma cells by arresting the cell cycle growth phase of G0-G1. This derivative retains the mechanism of COX-2 inhibitory and PI3K/Akt inhibitory activity which ultimately promotes apoptosis (Gowda et al. 2013). Another most effective compound called SeCNaspirin analog was developed. They found extremely selective toward cancer cells and cause cell cycle arrest in G1 and G2/M phases. This SeCN-aspirin analog induce apoptosis by activating caspase $3 / 7$ and PARP cleavage in colorectal cancer cells (Plano et al. 2016).

\section{Selenoureas}

Selenourea derivatives along with their corresponding thiourea analogues were synthesized. They were assessed for their antiproliferative effects in many human cancer cell lines. The study exhibited higher potency with $\mathrm{IC}_{50}$ values below $10 \mu \mathrm{M}$ in all cell lines tested and then further evaluated their capability with different colon cancer cell models. The compound assists the activation of caspase-dependent pathways and also helps in inhibition of cancer causing proteins. Nearly 17 ferrocenyl-selenoureas have been developed and they were studied for their DNA binding properties, antioxidant activity, cytotoxicity in neuroblastoma cell lines like MYCN2, SK-N-SH, liver hepatocarcinoma cell line Hepa1c1c7, and breast cancer cell line MCF-7. Most of the compounds exhibited cytotoxicity towards cancer cell lines (90\%) with low $\mu \mathrm{M}$ concentrations (Hussain et al. 2015). Another selenourea derivative was tested in vivo with prostate cancer mouse xenograft model and it suppressed tumor growth around $80 \%$ without any troublesome effects (Ibanez et al. 2012).

\section{Selenocarbonyl derivatives}

Several carbonyl-containing compounds have been chemically transformed into selone analogue derivatives and were tested for their biological activities in different models. The selone analogue of chrysin and tetramethylquercetin has been synthesized and this compound exhibited better antioxidant activity, cytotoxicity and in specific the $\mathrm{IC}_{50}$ in MCF-7 cells was lowered (Martins et al. 2015). Selenohydantoin another compound was evaluated in vitro against many 
cancer cell lines and they showed excellent anti-proliferative activities in low $\mu \mathrm{M}$ concentrations (Ivanenkov et al. 2016).

\section{Selenium nanoparticles for cancer treatment}

Currently the selenium nanoparticles have gained much interest as potential novel therapeutic mediators, because of their excessive biocompatibility, constancy and distinct selectivity. They are generally synthesized by three major routes (1) chemical based (2) biological and (3) physical (Maiyo and Singh 2017). Between them, chemical synthesis is considered the most common method to prepare selenium nanoparticles. In chemical synthesis, selenium in the form of selenite, selenious acid, or selenium dioxide were frequently used as precursors, reducing agents like ascorbic acid and glutathione are employed and stabilizing agents like chitosan and pectin helps in the selenium nanoparticles formation and maintenance (Qiu et al. 2018; Zhai et al. 2017). Synthesized selenium nanoparticles in the sodium selenite/ glutathione $\left(\mathrm{Na}_{2} \mathrm{SeO}_{3}-\mathrm{GSH}\right)$ redox system are inclined to gather in cancer cells and to present stronger pro-oxidant activity (Zhao et al. 2018a, b). For optimize their function, the chemically synthesized selenium nanoparticles are usually decorated with other bioactive molecules which can enhance the therapeutic effects upon certain types of cancers when compared with non-decorated selenium nanoparticles. Apart from direct therapeutic effects, chemically altered selenium nanoparticles can act as vehicles that endow the carried objects with favourable properties like low toxicity, high efficacy and tumor targeting. Markedly, chemically synthesized selenium nanoparticles were also observed as diagnostic agents, imaging mediators, and radio-sensitizers (Yang et al. 2017; Chen et al. 2018a, b; Zhao et al. 2018a, b; Abd-Rabou et al. 2019).

On comparison with chemically synthesized selenium nanoparticles, biologically synthesized nanoparticles appear to be eco-friendly, biocompatible, sustainable, economical and safer too (Wadhwani et al. 2016). These nanoparticles are synthesized using extracts or media from plant sources, bacteria, fungi and other organisms. The synthesized selenium nanoparticles exhibit varied biological activities like preventing DNA damage by UVB-induced and inhibiting the proliferation of cancer cells (Prasad et al. 2013). Until now, bacteria have been the most important source of biologically synthesized nanoparticles. Bacterial source which helps in the fabrication of selenium nanoparticles includes Bacillus licheniformis JS2, Ochrobactrum sp. MPV1, Streptomyces minutiscleroticus M10A62 and Acinetobacter sp. SW30 (Tugarova and Kamnev 2017; Ramya et al. 2015). Synthesis of selenium nanoparticles using bacteria is done by culturing the strains in the growth media containin sodium selenite at a concentration range from $0.5-2 \mathrm{mM}$. Under the stress condition of sodium selenite concentration $(0.5$ or $2 \mathrm{mM})$, these Ochrobactrum sp. MPV1 bacteria are capable of converting selenite to elemental Se by which selenium nanoparticles synthesis occur intra-cellularly and rather their medical applications remains unexplored (Zonaro et al. 2017). In another study selenium nanoparticles synthesized from Bacillus licheniformis strain JS2 have the capability to initiate necroptosis in PC-3 cell by the ROS-mediated activation controlled via Receptor-interacting protein kinase 1 (RIP1 kinase) (Saratale et al. 2018; Sonkusre and Cameotra 2017).

Biological synthesis of selenium nanoparticles using Plant sources is another interesting feature. By using simple refluxing method uniform size $(3-18 \mathrm{~nm})$ and shaped, selenium nanoballs were synthesized from dried Vitis vinifera (raisin) extracts and selenous acid (Sharma et al. 2014). These selenium nanoparticles synthesized from variety of plants sources has enormous potential in future though the exact mechanism of synthesis and their therapeutic applications remains mostly underexplored.

Synthesis of selenium nanoparticles using physical methods have been carried using pulsed laser ablation and gamma radiation (Quintana et al. 2002). Previous study showed that pure selenium nanoparticles synthesized by pulsed laser ablation in liquids were able to disturb the biofilm formation of a human pathogen Candida albicans, which highlights its potential for medical application. But still the application of these selenium nanoparticles synthesized by physical methods for cancer treatment and prevention is still undeveloped, which may be due to the equipment requirements (Guisbiers et al. 2017).

Selenium nanoparticles have great prospective not only in cancer treatment but also as diagnostic/imaging agents and more. Selenium nanoparticles exhibited anticancer effects in a series of cancers like hepatocarcinoma, breast cancer, colon adenocarcinoma, lymphoma, esophageal cancer, prostate cancer, ovarian cancer, and glioma (Maiyo and Singh 2017). Further studies and clinical trials are required to explain the possible applications of selenium nanoparticles in cancer treatment.

\section{Conclusion and future perspectives}

For the past few decades, research on the elemental selenium has reached its remarkable heights. Particularly its role in the synthesis of various types of selenoproteins and many regulatory metabolic pathways starting from the plant source to human's mechanistic approach. Throughout the years, many novel selenoproteins have been identified and annotated its importance in various aspects. This review is mainly focused on some of the functions of selenoproteins and their part in wound healing mechanism. Some of the predictable or possible routes like translational decoding of selenocysteine, biosynthesis of selenoproteins, systemic 
action of selenoproteins and their direct or indirect assimilation of selenoproteins in the process of wound healing are discussed. In near future those predicted routes can be experimentally proved and may help in resolve the mystery about the role of selenium in wound healing process. Selenium compounds have been reasonably beneficial in cancer treatment and diagnosis. Recent day's selenium nanoparticle has attracted considerable attention against various types of cancers. They will be playing critical role in cancer prevention and therapy in the near future. Many new selenium drugs pertaining to inflammations and other deficiencies/ diseases may also arise to prove the importance of selenium to the medical and pharmaceutical world.

Acknowledgements The authors wish to thank the management of Karpagam Academy of Higher Education, Coimbatore, India for providing University Research Fellowship (URF) to Ms. Sneha Hariharan (KAHE/RS/R1/RSF/2019/5) and without that support, writing a review on this topic could not be possible.

\section{Compliance with ethical standards}

Conflict of interest The authors declare that they have no competing interest.

\section{References}

Abbas N, Shaaban S, Abdel-latif E (2015) Synthesis and antitumor activity of some new symmetrical diselenide derivatives. Res $\mathbf{J}$ Pharm Biol Chem Sci 6(2015):1655-1664

Abd-Rabou AA, Shalby AB, Ahmed HH (2019) Selenium nanoparticles induce the chemo-sensitivity of fluorouracil nanoparticles in breast and colon cancer cells. Biol Trace Elem Res 187:80-91

Alanne M, Kristiansson K, Auro K, Silander K, Kuulasmaa K, Peltonen L, Salomaa V, Perola M (2007) Variation in the selenoprotein $\mathrm{S}$ gene locus is associated with coronary heart disease and ischemic stroke in two independent Finnish cohorts. Hum Genet 122:355-365

Alcolea V, Plano D, Karelia DN, Palop JA, Amin S, Sanmartin C, Sharma AK (2016) Novel seleno- and thio-urea derivatives with potent in vitro activities against several cancer cell lines. Eur J Med Chem 113:134-144

Alfthan G, Eurola M, Ekholm P, Venäläinen ER, Root T, Korkalainen K, Hartikainen H, Salminen P, Hietaniemi V, Aspila P, Aro A (2015) Effects of nationwide addition of selenium to fertilizers on foods, and animal and human health in Finland: from deficiency to optimal selenium status of the population. J Trace Elem Med Biol 31:142-147

Ali W, Álvarez-Pérez M, Marc MA, Salardón-Jiménez N, Handzlik J, Domínguez-Álvarez E (2018) The anticancer and chemopreventive activity of selenocyanate-containing compounds. Curr Pharmacol Rep 4:468-481

Allmang C, Wurth L, Krol A (2009) The selenium to selenoprotein pathway in eukaryotes: more molecular partners than anticipated. Biochim Biophys Acta 1790:1415-1423

Álvarez-Pérez M, Ali W, Marc MA, Handzlik J, Domínguez-Álvarez E (2018) Selenides and diselenides: a review of their anticancer and chemopreventive activity. Molecules 23:628

Arbogast S, Ferreiro A (2010) Selenoproteins and protection against oxidative stress: selenoprotein $\mathrm{N}$ as a novel player at the crossroads of redox signaling and calcium homeostasis. Antioxid Redox Signal 12:893-904

Ashton K, Hooper L, Harvey LJ, Hurst R, Casgrain A, Fairweather-Tait SJ (2009) Methods of assessment of selenium status in humans: a systematic review. Am J Clin Nutr 89:2025-2039

Azad GK, Tomar RS (2014) Ebselen, a promising antioxidant drug: mechanisms of action and targets of biological pathways. Mol Biol Rep 41:4865-4879

Baines A, Taylor-Parker M, Goulet AC, Renaud C, Gerner EW, Nelson MA (2002) Selenomethionine inhibits growth and suppresses cyclooxygenase-2 (COX-2) protein expression in human colon cancer cell lines. Cancer Biol Ther 1:370-374

Banuelos GS, Lin ZQ, Yin X (2013) Selenium in the environment and human health. CRC Press, Boca Raton, pp 1-248

Bedard K, Krause KH (2007) The NOX family of ROS-generating NADPH oxidases: physiology and pathophysiology. Physiol Rev 87:245-313

Benstoem C, Goetzenich A, Kraemer S, Borosch S, Manzanares W, Hardy G, Stoppe C (2015) Selenium and its supplementation in cardiovascular disease-what do we know? Nutrients 7:3094-3118

Berthier S, Arnaud J, Champelovier P, Col E, Garrel C, Cottet C, Boutonnat J, Laporte F, Faure P, Hazane-Puch F (2017) Anticancer properties of sodium selenite in human glioblastoma cell cluster spheroids. J Trace Elem Med Biol 44:161-176

Bhattacharya A, Seshadri M, Oven SD, Tóth K, Vaughan MM, Rustum YM (2008) Tumor vascular maturation and improved drug delivery induced by methylselenocysteine leads to therapeutic synergy with anticancer drugs. Clin Cancer Res 14:3926-3932

Bi X, Pohl N, Dong H, Yang W (2013) Selenium and sulindac are synergistic to inhibit intestinal tumorigenesis in Apc/p21 mice. J Hematol Oncol 6:8

Bischoff M, Kinzl L, Schmelz A (1999) The complicated wound. Der Unfallchirurg 102:797-804

Björnstedt M, Kumar S, Holmgren A (1992) Selenodiglutathione is a highly efficient oxidant of reduced thioredoxin and a substrate for mammalian thioredoxin reductase. J Biol Chem 267:8030-8034

Blass SC, Goost H, Burger C, Tolba RH, Stoffel-Wagner B, Stehle P, Ellinger S (2013) Extracellular micronutrient levels and pro-/ antioxidant status in trauma patients with wound healing disorders: results of a cross-sectional study. Nutr J 12:157

Böck A, Forchhammer K, Heider J, Leinfelder W, Sawers G, Veprek B, Zinoni F (1991) Selenocysteine: the 21st amino acid. Mol Microbiol 5:515-520

Boritzki TJ, Berry DA, Besserer JA, Cook PD, Fry DW, Leopold WR, Jackson RC (1985) Biochemical and antitumor activity of tiazofurin and its selenium analog (2-beta-D-ribofuranosyl-4-selenazolecarboxamide). Biochem Pharmacol 34:1109-1114

Brigelius-Flohé R, Flohé L (2017) Selenium and redox signaling. Arch Biochem Biophys 617:48-59

Brigelius-Flohe R, Maiorino M (2013) Glutathione peroxidases. Biochim Biophys Acta 1830:3289-3303

Brigelius-Flohé R, Müller M, Lippmann D, Kipp AP (2012) The yin and yang of nrf2-regulated selenoproteins in carcinogenesis. Int J Cell Biol 2012:1-8

Bubenik JL, Miniard AC, Driscoll DM (2014) Characterization of the UGA-recoding and SECIS-binding activities of SECIS-binding protein 2. RNA Biol 11:1402-1413

Buettner C, Harney JW, Berry MJ (1999) The Caenorhabditiselegans homologue of thioredoxin reductase contains a selenocysteine insertion sequence (SECIS) element that differs from mammalian SECIS elements but directs selenocysteine incorporation. J Biol Chem 274:21598-21602

Burk RF (2001) Selenium: recent clinical advances. Curr Opin Gastroenterol 17:162-166 
Burk RF, Hill KE (2005) Selenoprotein P: an extracellular protein with unique physical characteristics and a role in selenium homeostasis. Annu Rev Nutr 25:215-235

Burk RF, Hill KE (2009) Selenoprotein P-expression, functions, and roles in mammals. Biochim Biophys Acta 1790:1441-1447

Cao S, Durrani FA, Rustum YM (2004) Selective modulation of the therapeutic efficacy of anticancer drugs by selenium containing compounds against human tumor xenografts. Clin Cancer Res 10:2561-2569

Chakraborty P, Roy SS, Bhattacharya S (2015) Molecular mechanism behind the synergistic activity of diphenylmethyl selenocyanate and Cisplatin against murine tumor model. Anti-Cancer Agents Med Chem 15:501-510

Chambers I, Frampton J, Goldfarb P, Affara N, McBain W, Harrison PR (1986) The structure of the mouse glutathione peroxidase gene: the selenocysteine in the active site is encoded by the 'termination' codon, TGA. EMBO J 5:1221-1227

Chan JM, Darke AK, Penney KL, Tangen CM, Goodman PJ, Lee GS, Sun T, Peisch S, Tinianow AM, Rae JM, Klein EA (2016) Selenium-or vitamin E-related gene variants, interaction with supplementation, and risk of high-grade prostate cancer in SELECT. Cancer Epidemiol Biomark Prev 25:1050-1058

Chen F, Zhang XH, Hu XD, Liu PD, Zhang HQ (2018a) The effects of combined selenium nanoparticles and radiation therapy on breast cancer cells in vitro. Artif Cells Nanomed Biotechnol 46:937-948

Chen J, Berry MJ (2003) Selenium and selenoproteins in the brain and brain diseases. J Neurochem $86: 1-2$

Chen T, Wong YS (2008) Selenocystine induces apoptosis of A375 human melanoma cells by activating ROS-mediated mitochondrial pathway and p53 phosphorylation. Cell Mol Life Sci 65:2763-2775

Chen W, An J, Guo J, Wu Y, Yang L, Dai J, Gong K, Miao S, Xi S, Du J (2018b) Sodium selenite attenuates lung adenocarcinoma progression by repressing SOX2-mediated stemness. Cancer Chemother Pharmacol 81:885-895

Choi A, Jo MJ, Jung MJ, Kim HS, Yoon S (2015) Selenate specifically sensitizes drug-resistant cancer cells by increasing apoptosis via G2 phase cell cycle arrest without P-GP inhibition. Eur J Pharmacol 764:63-69

Chun OK, Floegel A, Chung SJ, Chung CE, Song WO, Koo SI (2009) Estimation of antioxidant intakes from diet and supplements in US adults. J Nutr 140:317-324

Cihalova K, Chudobova D, Michalek P, Moulick A, Guran R, Kopel P, Adam V, Kizek R (2015) Staphylococcus aureus and MRSA growth and biofilm formation after treatment with antibiotics and SeNPs. Int J Mol Sci 16:24656-24672

Coupland RM (1992) The Red Cross classification of war wounds: the EXCFVM scoring system. World J Surg 16:910-917

Cox AJ, Lehtinen AB, Xu J, Langefeld CD, Freedman BI, Carr JJ, Bowden DW (2013) Polymorphisms in the Selenoprotein S gene and subclinical cardiovascular disease in the Diabetes Heart Study. Acta diabetol 50:391-399

Crampsie MA, Pandey MK, Desai D, Spallholz J, Amin S, Sharma AK (2012) Phenylalkyl isoselenocyanates vs phenylalkyl isothiocyanates: thiol reactivity and its implications. Chem Biol Interact 200:28-37

Cubadda F, Aureli F, Ciardullo S, D'Amato M, Raggi A, Acharya R, Reddy RA, Prakash NT (2010) Changes in selenium speciation associated with increasing tissue concentrations of selenium in wheat grain. J Agric Food Chem 58:2295-2301

Curran JE, Jowett JB, Elliott KS, Gao Y, Gluschenko K, Wang J, Azim DM, Cai G, Mahaney MC, Comuzzie AG, Dyer TD (2005) Genetic variation in selenoprotein $\mathrm{S}$ influences inflammatory response. Nat Genet 37(1234):1241
Das JK, Sarkar S, Hossain SU, Chakraborty P, Das RK, Bhattacharya S (2013) Diphenylmethyl selenocyanate attenuates malachite green induced oxidative injury through antioxidation and inhibition of DNA damage in mice. Indian J Med Res 137:1163-1173

Davis CD, Tsuji PA, Milner JA (2012) Selenoproteins and cancer prevention. Annu Rev Nutr 32:73-95

De Freitas AS, Rocha JB (2011) Diphenyl diselenide and analogs are substrates of cerebral rat thioredoxin reductase: a pathway for their neuroprotective effects. Neurosci Lett 503:1-5

De Jesus LA, Hoffmann PR, Michaud T, Forry EP, Small-Howard A, Stillwell RJ, Morozova N, Harney JW, Berry MJ (2006) Nuclear assembly of UGA decoding complexes on selenoprotein mRNAs: a mechanism for eluding nonsense-mediated decay? Mol Cell Biol 26:1795-1805

De Souza MP, Pilon-Smits EA, Lytle CM, Hwang S, Tai J, Honma TS, Yeh L, Terry N (1998) Rate-limiting steps in selenium assimilation and volatilization by Indian mustard. Plant Physiol 117:1487-1494

Dentice M, Marsili A, Zavacki A, Larsen PR, Salvatore D (2013) The deiodinases and the control of intracellular thyroid hormone signaling during cellular differentiation. Biochim Biophys Acta 1830:3937-3945

Diamond AM, Choi IS, Crain PF, Hashizume T, Pomerantz SC, Cruz R, Steer CJ, Hill KE, Burk RF, McCloskey JA (1993) Dietary selenium affects methylation of the wobble nucleoside in the anticodon of selenocysteine tRNA ([Ser] Sec). J Biol Chem 268:14215-14223

Dominguez-Alvarez E, Plano D, Font M, Calvo A, Prior C, Jacob C, Palop JA, Sanmartin C (2014) Synthesis and antiproliferative activity of novel selenoester derivatives. Eur J Med Chem 73:153-166

Domokos-Szabolcsy E, Marton L, Sztrik A, Babka B, Prokisch J, Fari M (2012) Accumulation of red elemental selenium nanoparticles and their biological effects in Nicotiniatabacum. Plant Growth Regul 68:525-531

Drahoňovský J, Száková J, Mestek O, Tremlová J, Kaňa A, Najmanová J, Tlustoš P (2014) Selenium uptake, transformation and interelement interactions by selected wildlife plant species after foliar selenate application. Environ Exper Bot 125:12-19

Ducros V, Favier A (2004) Selenium metabolism. EMC Endocrinol Nutr 1:19-28

Effraimidis G, Wiersinga WM (2014) Mechanisms in endocrinology: autoimmune thyroid disease: old and new players. Eur J Endocrinol 170:241-252

El-Ramady H, Abdalla N, Alshaal T, El-Henawy A, Salah ED, Shams MS, Shalaby T, Bayoumi Y, Elhawat N, Shehata S, Sztrik A (2015) Selenium and its role in higher plants. Pollutants in buildings, water and living organisms. Springer, Cham, pp 235-296

Endo M, Hasegawa H, Kaneko T, Kanno C, Monma T, Kano M, Shinohara F, Takahashi T (2017) Antitumor activity of selenium compounds and its underlying mechanism in human oral squamous cell carcinoma cells: a preliminary study. J Oral Maxillofac Surg Med Pathol 29:17-23

Enqvist M, Nilsonne G, Hammarfjord O, Wallin RPA, Bjorkstrom NK, Bjornstedt M, Hjerpe A, Ljunggren HG, Dobra K, Malmberg KJ, Carlsten M (2011) Selenite induces posttranscriptional blockade of HLA-E expression and sensitizes tumor cells to CD94/ NKG2A-Positive NK Cells. J Immunol 187:3546-3554

Esaki N, Sawada S, Tanaka H, Soda K (1982) Enzymatic preparation of $\alpha$-and $\beta$-deuterated or tritiated amino acids with 1-methionine $\gamma$-lyase. Anal Biochem 119:281-285

Facompre ND, Sinha I, El-Bayoumy K, Pinto JT, Sinha R (2012) Remarkable inhibition of mTOR signaling by the combination of rapamycin and 1,4-phenylenebis(methylene) selenocyanate in human prostate cancer cells. Int J Cancer 131:2134-2142 
Fairweather-Tai SJ, Collings R, Hurst R (1491S) Selenium bioavailability: current knowledge and future research requirements. Am J Clin Nutr 91:1484S-1491S

Fairweather-Tait SJ, Collings R, Hurst R (2010) Selenium bioavailability: current knowledge and future research requirements. Am J Clin Nutr 91:1484-1491

Fan C, Zheng W, Fu X, Li X, Wong YS, Chen T (2014) Enhancement of auranofin induced lung cancer cell apoptosis by selenocystine, a natural inhibitor of TrxR1 in vitro and in vivo. Cell Death Dis 5:e1191

Fernandes AP, Gandin V (2015) Selenium compounds as therapeutic agents in cancer. Biochim Biophys Acta 1850:1642-1660

Florian S, Krehl S, Loewinger M, Kipp A, Banning A, Esworthy S, Chu FF, Brigelius-Flohé R (2010) Loss of GPx2 increases apoptosis, mitosis, and GPx 1 expression in the intestine of mice. Free Radic Biol Med 49:1694-1702

Forootanfar H, Adeli-Sardou M, Nikkhoo M, Mehrabani M, AmirHeidari B, Shahverdi AR, Shakibaie M (2014) Antioxidant and cytotoxic effect of biologically synthesized selenium nanoparticles in comparison to selenium dioxide. J Trace Elem Med Biol 28:75-79

Franchetti P, Cappellacci L, Sheikha GA, Jayaram HN, Gurudutt VV, Sint T, Schneider BP, Jones WD, Goldstein BM, Perra G, De Montis A, Loi AG, La Colla P, Grifantini M (1997) Synthesis, structure, and antiproliferative activity of selenophenfurin, an inosine 5'-monophosphate dehydrogenase inhibitor analogue of selenazofurin. J Med Chem 40:1731-1737

Gandin V, Khalkar P, Braude J, Fernandes AP (2018) Organic selenium compounds as potential chemotherapeutic agents for improved cancer treatment. Free Radic Biol Med 127:80-97

Ganyc D, Talbot S, Konate F, Jackson S, Schanen B, Cullen W, Self WT (2006) Impact of trivalent arsenicals on selenoprotein synthesis. Environ Health Perspect 115:346-353

Gao Y, Feng HC, Walder K, Bolton K, Sunderland T, Bishara N, Quick M, Kantham L, Collier GR (2004) Regulation of the selenoprotein SelS by glucose deprivation and endoplasmic reticulum stress-SelS is a novel glucose-regulated protein. FEBS Lett 563:185-190

Gao Y, Hannan NR, Wanyonyi S, Konstantopolous N, Pagnon J, Feng HC, Jowett JB, Kim KH, Walder K, Collier GR (2006) Activation of the selenoprotein SEPS1 gene expression by pro-inflammatory cytokines in HepG2 cells. Cytokine 33:246-251

Gao Y, Pagnon J, Feng HC, Konstantopolous N, Jowett JB, Walder K, Collier GR (2007) Secretion of the glucose-regulated selenoprotein SEPS1 from hepatoma cells. Biochem Biophys Res Commun 356:636-641

Gebeyehu G, Marquez VE, Van Cott A, Cooney DA, Kelley JA, Jayaram HN, Ahluwalia GS, Dion RL, Wilson YA, Johns DG (1985) Ribavirin, tiazofurin, and selenazofurin: mononucleotides and nicotinamide adenine dinucleotide analogues. Synthesis, structure, and interactions with IMP dehydrogenase. J Med Chem 28:99-105

Georgieva E, Ivanova D, Zhelev Z, Bakalova R, Gulubova M, Aoki I (2017) Mitochondrial dysfunction and redox imbalance as a diagnostic marker of "free radical diseases". Anticancer Res 37:5373-5381

Ghosh P, Roy SS, Basu A, Bhattacharjee A, Bhattacharya S (2015) Sensitization of cisplatin therapy by a naphthalimide based organoselenium compound through modulation of antioxidant enzymes and p53 mediated apoptosis. Free Radic Res 49:453-471

Gill SE, Parks WC (2008) Metalloproteinases and their inhibitors: regulators of wound healing. Int J Biochem Cell Biol 40:1334-1347

Gowda R, Madhunapantula SV, Desai D, Amin S, Robertson GP (2013) Simultaneous targeting of COX-2 and AKT using selenocoxib1-GSH to inhibit melanoma. Mol Cancer Ther 12:3-15
Guisbiers G, Lara HH, Mendoza-Cruz R, Naranjo G, Vincent BA, Peralta XG, Nash KL (2017) Inhibition of Candidaalbicans biofilm by pure selenium nanoparticles synthesized by pulsed laser ablation in liquids. Nanomedicine 13:1095-1103

Guo P, Wang Q, Liu J, Liu L, Zhao P, Cao Y, Liu Y, Qi C (2013a) Preparation of two organoselenium compounds and their induction of apoptosis to SMMC-7221 cells. Biol Trace Elem Res 154:304-311

Guo P, Zhao P, Liu J, Ma H, Bai J, Cao Y, Liu Y, He H, Qi C (2013b) Preparation of a novel organoselenium compound and its anticancer effects on cervical cancer cell line HeLa. Biol Trace Elem Res 151:301-306

Gupta A, Singh RL, Raghubir R (2002) Antioxidant status during cutaneous wound healing in immunocompromised rats. Mol Cell Biochem 241:1-7

Hanavan PD, Borges CR, Katchman BA, Faigel DO, Ho TH, Ma CT, Sergienko EA, Meurice N, Petit JL, Lake DF (2015) Ebselen inhibits QSOX1 enzymatic activity and suppresses invasion of pancreatic and renal cancer cell lines. Oncotarget 6:18418-18428

Hart DJ, Fairweather-Tait SJ, Broadley MR, Dickinson SJ, Foot I, Knott P, McGrath SP, Mowat H, Norman K, Scott PR, Stroud JL (2011) Selenium concentration and speciation in biofortified flour and bread: retention of selenium during grain biofortification, processing and production of Se-enriched food. Food Chem 126:1771-1778

Hatfield DL, Yoo MH, Carlson BA, Gladyshev VN (2009) Selenoproteins that function in cancer prevention and promotion. Biochim Biophys Acta 1790:1541-1545

Hu B, Cheng R, Gao X, Pan X, Kong F, Liu X, Xu K, Tang B (2018) Targetable mesoporous Silica nanoprobes for mapping the subcellular distribution of $\mathrm{H} 2 \mathrm{Se}$ in cancer cells. ACS Appl Mater Interfaces 10:17345-17351

Hussain RA, Badshah A, Pezzuto JM, Ahmed N, Kondratyuk TP, Park EJ (2015) Ferrocene incorporated selenoureas as anticancer agents. J Photochem Photobiol B Biol 148:197-208

Ibanez E, Agliano A, Prior C, Nguewa P, Redrado M, GonzalezZubeldia I, Plano D, Palop JA, Sanmartín C, Calvo A (2012) The quinoline imidoselenocarbamate EI201 blocks the AKT/ mTOR pathway and targets cancer stem cells leading to a strong antitumor activity. Curr Med Chem 19:3031-3043

Iuchi Y, Roy D, Okada F, Kibe N, Tsunoda S, Suzuki S, Takahashi M, Yokoyama H, Yoshitake J, Kondo S, Fujii J (2010) Spontaneous skin damage and delayed wound healing in SOD1-deficient mice. Mol Cell Biochem 341:181-194

Ivanenkov YA, Veselov MS, Rezekin IG, Skvortsov DA, Sandulenko YB, Polyakova MV, Bezrukov DS, Vasilevsky SV, Kukushkin ME, Moiseeva AA, Finko AV, Koteliansky VE, Klyachko NL, Filatova LA, Beloglazkina EK, Zyk NV, Majouga AG (2016) Synthesis, isomerization and biological activity of novel 2-selenohydantoin derivatives. Bioorg Med Chem 24:802-811

Jackson MI, Combs GF Jr (2008) Selenium and anticarcinogenesis: underlying mechanisms. Curr Opin Clin Nutr Metab Care 11:718-726

Jariwalla RJ, Gangapurkar B, Nakamura D (2009) Differential sensitivity of various human tumour-derived cell types to apoptosis by organic derivatives of selenium. Br J Nutr 101:182-189

Jiang C, Wang Z, Ganther H, Lu J (2001) Caspases as key executors of methyl selenium-induced apoptosis (anoikis) of DU-145 prostate cancer cells. Cancer Res 61:3062-3070

Jiang C, Wang Z, Ganther H, Lu J (2002) Distinct effects of methylseleninic acid versus selenite on apoptosis, cell cycle, and protein kinase pathways in DU145 human prostate cancer cells. Mol Cancer Ther 1:1059-1066

Junior ES, Wadt LH, Silva KE, Lima RM, Batista KD, Guedes MC, Carvalho GS, Carvalho TS, Reis AR, Lopes G, Guilherme LR 
(2017) Natural variation of selenium in Brazil nuts and soils from the Amazon region. Chemosphere 188:650-658

Kieliszek M, Lipinski B, Blazejak S (2017) Application of sodium selenite in the prevention and treatment of cancers. Cells 6:39

Kim T, Jung U, Cho DY, Chung AS (2001) Se-Methylselenocysteine induces apoptosis through caspase activation in HL-60 cells. Carcinogenesis 22:559-565

Köhrle J, Brigelius-Flohé R, Böck A, Gärtner R, Meyer O, Flohé L (2000) Selenium in biology: facts and medical perspectives. Biol Chem 381:849-864

Krishnegowda G, Prakasha Gowda AS, Tagaram HR, Carroll KF, Irby RB, Sharma AK, Amin S (2011) Synthesis and biological evaluation of a novel class of isatin analogs as dual inhibitors of tubulin polymerization and Akt pathway. Bioorg Med Chem 19:6006-6014

Kryukov GV, Castellano S, Novoselov SV, Lobanov AV, Zehtab O, Guigó R, Gladyshev VN (2003) Characterization of mammalian selenoproteomes. Science 300:1439-1443

Kuroki F, Matsumoto T, Iida M (2003) Selenium is depleted in Crohn's disease on enteral nutrition. Dig dis 21:266-270

Labunskyy VM, Hatfield DL, Gladyshev VN (2014) Selenoproteins: molecular pathways and physiological roles. Physiol Rev 94:739-777

Last K, Maharaj L, Perry J, Strauss S, Fitzgibbon J, Lister TA, Joel S (2006) The activity of methylated and non-methylated selenium species in lymphoma cell lines and primary tumours. Ann Oncol 17:773-779

Lau ATY, Tan HW, Xu YM (2017) Epigenetic effects of dietary trace elements. Curr Pharmacol Rep 3:232-241

Läuchli A (1993) Selenium in plants: uptake, functions, and environmental toxicity. Bot Acta 106:455-468

Lazarus GS, Cooper DM, Knighton DR, Margolis DJ, Percoraro RE, Rodeheaver G, Robson MC (1994) Definitions and guidelines for assessment of wounds and evaluation of healing. Wound Repair Regen 2:165-170

Lei C, Niu X, Wei J, Zhu J, Zhu Y (2009) Interaction of glutathione peroxidase-1 and selenium in endemic dilated cardiomyopathy. Clin Chim Acta 399:102-108

Li Z, Carrier L, Belame A, Thiyagarajah A, Salvo VA, Burow ME, Rowan BG (2009) Combination of methylselenocysteine with tamoxifen inhibits MCF-7 breast cancer xenografts in nude mice through elevated apoptosis and reduced angiogenesis. Breast Cancer Res Treat 118:33-43

Lipinski B (2017) Sodium selenite as an anticancer agent. Anticancer Agents Med Chem 17:658-661

Liu M, Fu J, Li J, Wang L, Tan Q, Ren X, Peng Z, Zeng H (2010) Preparation of triblock copolymer micelles loading novel organoselenium anticancer drug BBSKE and study of tissue distribution of copolymer micelles by imaging in vivo method. Int $\mathrm{J}$ Pharm 391:292-304

Liu Y, Zhao H, Zhang Q, Tang J, Li K, Xia XJ, Wang KN, Li K, Lei XG (2012) Prolonged dietary selenium deficiency or excess does not globally affect selenoprotein gene expression and/or protein production in various tissues of pigs. J Nutr 142:1410-1416

Lobb RJ, Jacobson GM, Cursons RT, Jameson MB (2018) The interaction of selenium with chemotherapy and radiation on normal and malignant human mononuclear blood cells. Int J Mol Sci 19:3167

Lu J, Holmgren A (2009) Selenoproteins. J Biol Chem 284:723-727

Lucas DL, Robins RK, Knight RD, Wright DG (1983) Induced maturation of the human promyelocytic leukemia cell line, HL-60, by 2-beta-D-ribofuranosylselenazole-4-carboxamide. Biochem Biophys Res Commun 115:971-980

Maiorino M, Scapin M, Ursini F, Biasolo M, Bosello V, Flohé L (2003) Distinct promoters determine alternative transcription of gpx-4 into phospholipid-hydroperoxide glutathione peroxidase variants. J Biol Chem 278:34286-34290
Maiyo F, Singh M (2017) Selenium nanoparticles: potential in cancer gene and drug delivery. Nanomedicine 12:1075-1089

Malhotra S, Welling MN, Mantri SB, Desai K (2016) In vitro and in vivo antioxidant, cytotoxic, and anti-chronic inflammatory arthritic effect of selenium nanoparticles. J Biomed Mater Res B 104:993-1003

Martin JL, Hurlbut JA (1976) Tissue selenium levels and growth responses of mice fed selenomethionine, Se-methyl selenocysteine or sodium selenite. Phosphorous Sulfur Rel Elem 1:295-300

Martin P (1997) Wound healing-aiming for perfect skin regeneration. Science 276:75-81

Martins IL, Charneira C, Gandin V, Ferreira da Silva JL, Justino GC, Telo JP, Vieira AJSC, Marzano C, Antunes AMM (2015) Selenium-containing chrysin and quercetin derivatives: attractive scaffolds for cancer therapy. J Med Chem 58:4250-4265

Mehta SL, Mendelev N, Kumari S, Li PA (2013) Overexpression of human selenoprotein $\mathrm{H}$ in neuronal cells enhances mitochondrial biogenesis and function through activation of protein kinase A, protein kinase $\mathrm{B}$, and cyclic adenosine monophosphate response element-binding protein pathway. Int J Biochem Cell Biol 45:604-611

Meija J, Coplen TB, Berglund M, Brand WA, De Bièvre P, Gröning M, Prohaska T (2016) Isotopic compositions of the elements 2013 (IUPAC technical Report). Pure Appl Chem 88:293-306

Meyer HA, Endermann T, Stephan C, Stoedter M, Behrends T, Wolff I, Jung K, Schomburg L (2012) Selenoprotein P status correlates to cancer-specific mortality in renal cancer patients. PLoS ONE 7:e46644

Misra S, Boylan M, Selvam A, Spallholz JE, Bjornstedt M (2015) Redox-active selenium compounds-from toxicity and cell death to cancer treatment. Nutrients 7:3536-3556

Mistry HD, Broughton Pipkin F, Redman CW, Poston L (2012) Selenium in reproductive health. Am J Obstet Gynecol 206:21-30

Moore MA, Wandera RC, Xia YM, Du SH, Butler JA, Whanger PD (2000) Selenium supplementation of Chinese women with habitually low selenium intake increases plasma selenium, plasma glutathione peroxidase activity, and milk selenium, but not milk glutathione peroxidase activity. J Nutr Biochem 11:341-347

Mostert V, Dreher I, Köhrle J, Wolff S, Abel J (2001) Modulation of selenoprotein P expression by TGF- $\beta 1$ is mediated by Smad proteins. BioFactors 14:135-142

Muller A, Cadenas E, Graf P, Sies H (1984) A novel biologically active selenoorganic compound-I. Glutathione peroxidase-like activity in vitro and antioxidant capacity of PZ 51 (Ebselen). Biochem Pharmacol 33:3235-3239

Mustacich D, Powis G (2000) Thioredoxin reductase. Biochem J 346:1-8

Navarro-Alarcon M, Cabrera-Vique C (2008) Selenium in food and the human body: a review. Sci Total Environ 400:115-141

Nedel F, Campos VF, Alves D, McBride AJ, Dellagostin OA, Collares T, Savegnago L, Seixas FK (2012) Substituted diaryl diselenides: cytotoxic and apoptotic effect in human colon adenocarcinoma cells. Life Sci 91:345-352

Neuhierl B, Böck A (1996) On the mechanism of selenium tolerance in selenium-accumulating plants: purification and characterization of a specific selenocysteine methyl transferase from cultured cells of Astragalusbisculatus. Eur J Biochem 239:235-238

Olm E, Fernandes AP, Hebert C, Rundlöf AK, Larsen EH, Danielsson O, Björnstedt M (2009) Extracellular thiol-assisted selenium uptake dependent on the xc-cystine transporter explains the cancer-specific cytotoxicity of selenite. PNAS 106:11400-11405

Olson GE, Winfrey VP, Nagdas SK, Hill KE, Burk RF (2005) Selenoprotein $\mathrm{P}$ is required for mouse sperm development. Biol Reprod 73:201-211

Pacuła AJ, Kaczor KB, Wojtowicz A, Antosiewicz J, Janecka A, Długosz A, Janecki T, Ścianowski J (2017) New glutathione 
peroxidase mimetics-insights into antioxidant and cytotoxic activity. Bioorg Med Chem 25:126-131

Papp LV, Holmgren A, Khanna KK (2010) Selenium and selenoproteins in health and disease. Antioxid Redox Signal 12:793-795

Papp LV, Lu J, Holmgren A, Khanna KK (2007) From selenium to selenoproteins: synthesis, identity, and their role in human health. Antioxid Redox Signal 9:775-806

Papp LV, Wang J, Kennedy D, Boucher D, Zhang Y, Gladyshev VN, Singh RN, Khanna KK (2008) Functional characterization of alternatively spliced human SECISBP2 transcript variants. Nucleic Acids Res 36:7192-7206

Parnham MJ, Sies H (2013) The early research and development of ebselen. Biochem Pharmacol 86:1248-1253

Pascual A, Aranda A (2013) Thyroid hormone receptors, cell growth and differentiation. Biochim Biophys Acta 1830:3908-3916

Peng F, Guo X, Li Z, Li C, Wang C, Lv W, Wang J, Xiao F, Kamal M, Yuan C (2016) Antimutagenic effects of selenium-enriched polysaccharides from pyracantha fortuneana through suppression of cytochrome P450 1A subfamily in the mouse liver. Molecules 21:1731

Plano D, Karelia DN, Pandey MK, Spallholz JE, Amin S, Sharma AK (2016) Design, synthesis, and biological evaluation of novel selenium (Se-NSAID) molecules as anticancer agents. J Med Chem 59:1946-1959

Plano D, Sanmartin C, Moreno E, Prior C, Calvo A, Palop JA (2007) Novel potent organoselenium compounds as cytotoxic agents in prostate cancer cells. Bioorg Med Chem Lett 17:6853-6859

Poerschke RL, Moos PJ (2011) Thioredoxin reductase 1 knockdown enhances selenazolidine cytotoxicity in human lung cancer cells via mitochondrial dysfunction. Biochem Pharmacol 81:211-221

Posser T, de Paula MT, Franco JL, Leal RB, da Rocha JB (2011) Diphenyl diselenide induces apoptotic cell death and modulates ERK1/2 phosphorylation in human neuroblastoma SH-SY5Y cells. Arch Toxicol 85:645-651

Prasad KS, Patel H, Patel T, Patel K, Selvaraj K (2013) Biosynthesis of Se nanoparticles and its effect on UV-induced DNA damage. Colloids Surf B Biointerfaces 103:261-266

Prasad S, Gupta SC, Tyagi AK (2017) Reactive oxygen species (ROS) and cancer: role of antioxidative nutraceuticals. Cancer Lett 387:95-105

Qiu WY, Wang YY, Wang M, Yan JK (2018) Construction, stability, and enhanced antioxidant activity of pectin-decorated selenium nanoparticles. Colloids Surf B Biointerfaces 170:692-700

Quintana M, Haro-Poniatowski E, Morales J, Batina N (2002) Synthesis of selenium nanoparticles by pulsed laser ablation. Appl Surf Sci 195:175-186

Rahmanto AS, Davies MJ (2012) Selenium-containing amino acids as direct and indirect antioxidants. IUBMB Life 64:863-871

Ramya S, Shanmugasundaram T, Balagurunathan R (2015) Biomedical potential of actinobacterially synthesized selenium nanoparticles with special reference to anti-biofilm, anti-oxidant, wound healing, cytotoxic and anti-viral activities. J Trace Elem Med Biol 32:30-39

Rasmussen LB, Schomburg L, Köhrle J, Pedersen IB, Hollenbach B, Hög A, Ovesen L, Perrild H, Laurberg P (2011) Selenium status, thyroid volume, and multiple nodule formation in an area with mild iodine deficiency. Eur J Endocrinol 164:585-590

Rayman MP (2000) The importance of selenium to human health. Lancet 356:233-241

Rayman MP (2002) The argument for increasing selenium intake. Proc Nutr Soc 61:203-215

Rayman MP (2005) Selenium in cancer prevention: a review of the evidence and mechanism of action. Proc Nutr Soc 64:527-542

Rayman MP (2008) Food-chain selenium and human health: emphasis on intake. Br J Nutr 100:254-268
Reeves MA, Hoffmann PR (2009) The human selenoproteome: recent insights into functions and regulation. Cell Mol Life Sci 66:2457-2478

Romano B, Plano D, Encio I, Palop JA, Sanmartin C (2015) In vitro radical scavenging and cytotoxic activities of novel hybrid selenocarbamates. Bioorg Med Chem 23:1716-1727

Ronai Z, Tillotson JK, Traganos F, Darzynkiewicz Z, Conaway CC, Upadhyaya P, el-Bayoumy K (1995) Effects of organic and inorganic selenium compounds on rat mammary tumor cells. Int J Cancer 63:428-434

Saratale RG, Karuppusamy I, Saratale GD, Pugazhendhi A, Kumar G, Park Y, Ghodake GS, Bharagava RN, Banu JR, Shin HS (2018) A comprehensive review on green nanomaterials using biological systems: recent perception and their future applications. Colloids Surf B Biointerfaces 170:20-35

Schmutzler C, Mentrup B, Schomburg L, Hoang-Vu C, Herzog V, Köhrle J (2007) Selenoproteins of the thyroid gland: expression, localization and possible function of glutathione peroxidase 3 . Biol Chem 388:1053-1059

Schomburg L (2012) Selenium, selenoproteins and the thyroid gland: interactions in health and disease. Nat Rev Endocrinol 8:160-171

Schomburg L, Köhrle J (2008) On the importance of selenium and iodine metabolism for thyroid hormone biosynthesis and human health. Mol Nutr Food Res 52:1235-1246

Schomburg L, Schweizer U, Holtmann B, Flohé L, Sendtner M, Köhrle $\mathrm{J}$ (2003) Gene disruption discloses role of selenoprotein P in selenium delivery to target tissues. Biochem J 370:397-402

Schomburg L, Schweizer U, Köhrle J (2004) Selenium and selenoproteins in mammals: extraordinary, essential, enigmatic. Cell Mol Life Sci 61:1988-1995

Schröterová L, Králová V, Voráčová A, Hašková P, Rudolf E, Červinka M (2009) Antiproliferative effects of selenium compounds in colon cancer cells: comparison of different cytotoxicity assays. Toxicol Vitr 23:1406-1411

Selenius M, Rundlöf AK, Olm E, Fernandes AP, Björnstedt M (2010) Selenium and the selenoprotein thioredoxin reductase in the prevention, treatment and diagnostics of cancer. Antioxid Redox Signal 12:867-880

Sen CK (2009) Wound healing essentials: let there be oxygen. Wound Repair Regen 17:1-8

Sen CK, Roy S (2008) Redox signals in wound healing. Biochim Biophys Acta 1780:1348-1361

Shaaban S, Negm A, Ashmawy AM, Ahmed DM, Wessjohann LA (2016) Combinatorial synthesis, in silico, molecular and biochemical studies of tetrazolederived organic selenides with increased selectivity against hepatocellular carcinoma. Eur J Med Chem 122:55-71

Shaaban S, Negm A, Sobh MA, Wessjohann LA (2015) Organoselenocyanates and symmetrical diselenides redox modulators: design, synthesis and biological evaluation. Eur J Med Chem 97:190-201

Shakibaie M, Mohazab NS, Mousavi SA (2015) Antifungal activity of selenium nanoparticles synthesized by bacillus species Msh-1 against Aspergillusfumigatus and Candidaalbicans. Jundishapur J Microbiol 8:e26381

Sharma G, Sharma AR, Bhavesh R, Park J, Ganbold B, Nam JS, Lee SS (2014) Biomolecule-mediated synthesis of selenium nanoparticles using dried Vitisvinifera (raisin) extract. Molecules 19:2761-2770

Shen Q, Fan L, Newburger PE (2006) Nuclease sensitive element binding protein 1 associates with the selenocysteine insertion sequence and functions in mammalian selenoprotein translation. J Cell Physiol 207:775-783

Shi C, Yu L, Yang F, Yan J, Zeng H (2003) A novel organoselenium compound induces cell cycle arrest and apoptosis in prostate cancer cell lines. Biochem Biophys Res Commun 309:578-583 
Shigemi Z, Manabe K, Hara N, Baba Y, Hosokawa K, Kagawa H, Watanabe T, Fujimuro M (2017) Methylseleninic acid and sodium selenite induce severe ER stress and subsequent apoptosis through UPR activation in PEL cells. Chem Biol Interact 266:28-37

Shin SH, Yoon MJ, Kim M, Kim JI, Lee SJ, Lee YS, Bae S (2007) Enhanced lung cancer cell killing by the combination of selenium and ionizing radiation. Oncol Rep 17:209-216

Sidoryk K, Rarova L, Oklestkova J, Pakulski Z, Strnad M, Cmoch P, Luboradzki R (2016) Synthesis of 28a-homoselenolupanes and 28a-homoselenolupane saponins. Org Biomol Chem 14:10238-10248

Singh U, Null K, Sinha R (2008) In vitro growth inhibition of mouse mammary epithelial tumor cells by methylseleninic acid: involvement of protein kinases. Mol Nutr Food Res 52:1281-1288

Sneddon AA, Wu HC, Farquharson A, Grant I, Arthur JR, Rotondo D, Choe SN, Wahle KW (2003) Regulation of selenoprotein GPx4 expression and activity in human endothelial cells by fatty acids, cytokines and antioxidants. Atherosclerosis 171:57-65

Sonkusre P, Cameotra SS (2017) Biogenic selenium nanoparticles induce ROS-mediated necroptosis in PC-3 cancer cells through TNF activation. J Nanobiotechnol 15:1-12

Squires JE, Berry MJ (2008) Eukaryotic selenoprotein synthesis: mechanistic insight incorporating new factors and new functions for old factors. IUBMB Life 60:232-235

Srivastava PC, Robins RK (1983) Synthesis and antitumor activity of 2-beta-D-ribofuranosylselenazole-4-carboxamide and related derivatives. J Med Chem 26:445-448

Stadtman ER (1990) Metal ion-catalyzed oxidation of proteins: biochemical mechanism and biological consequences. Free Radic Biol Med 9:315-325

Steiling H, Munz B, Werner S, Brauchle M (1999) Different types of ROS-scavenging enzymes are expressed during cutaneous wound repair. Exp Cell Res 247:484-494

Stolzoff M, Webster TJ (2016) Reducing bone cancer cell functions using selenium nanocomposites. J Biomed Mater Res B 104:476-482

Stone CA, Kawai K, Kupka R, Fawzi WW (2010) Role of selenium in HIV infection. Nutr Rev 68:671-681

Sutter ME, Thomas JD, Brown J, Morgan B (2008) Selenium toxicity: a case of selenosis caused by a nutritional supplement. Ann Intern Med 148:970-971

Suzuki KT (2005) Metabolomics of selenium: Se metabolites based on speciation studies. J Health sci 51:107-114

Suzuki KT, Kurasaki K, Ogawa S, Suzuki N (2006) Metabolic transformation of methyl seleninic acid through key selenium intermediate selenide. Toxicol Appl Pharmacol 215:189-197

Suzuki KT, Kurasaki K, Suzuki N (2007) Selenocysteine $\beta$-lyase and methylselenol demethylase in the metabolism of Se-methylated selenocompounds into selenide. Biochim Biophys Acta Gen Subj 1770:1053-1061

Suzuki KT, Tsuji Y, Ohta Y, Suzuki N (2008) Preferential organ distribution of methylselenol source Se-methylselenocysteine relative to methylseleninic acid. Toxicol Appl Pharmacol 227:76-83

Suzuki M, Endo M, Shinohara F, Echigo S, Rikiishi H (2010a) Differential apoptotic response of human cancer cells to organoselenium compounds. Cancer Chemother Pharmacol 66:475-484

Suzuki YJ, Carini M, Butterfield DA (2010b) Protein carbonylation. Antioxid Redox Signal 12:323-325

Takeda T (2015) Post-translational activation of non-selenium glutathione peroxidase of Chlamydomonasreinhardtii by specific incorporation of selenium. Biochem Biophys Rep 4:39-43

Talbi W, Ghazouani T, Braconi D, Ben Abdallah R, Raboudi F, Santucci A, Fattouch S (2019) Effects of selenium on oxidative damage and antioxidant enzymes of eukaryotic cells: wine Saccharomycescerevisiae. J Appl Microbiol 126:555-566
Tan HW, Xu YM, Wu DD, Lau ATY (2018) Recent insights into human bronchial proteomics-how are we progressing and what is next? Expert Rev Proteom 15:113-130

Tan Q, Li J, Yin HW, Wang LH, Tang WC, Zhao F, Liu XM, Zeng HH (2010) Augmented antitumor effects of combination therapy of cisplatin with ethaselen as a novel thioredoxin reductase inhibitor on human A549 cell in vivo. Investig New Drugs 28:205-215

Tan Q, Ren XY, Li J, Wang F, Deng SJ, Zeng HH (2009) Correlation of plasma thioredoxin reductase activity to growth of $\mathrm{H} 22$ hepatocellular carcinoma xenografts in Kunming mice. Chin J Cancer 28:472-477

Terry N, Zayed AM, De Souza MP, Tarun AS (2000) Selenium in higher plants. Annu Rev Plant Biol 51:401-432

Thabet NM, Moustafa EM (2017) Synergistic effect of Ebselen and gamma radiation on breast cancer cells. Int J Radiat Biol 93:784-792

Thomson CD (2004) Assessment of requirements for selenium and adequacy of selenium status: a review. Eur J Clin Nutr 58:391-402

Tinggi U (2008) Selenium: its role as antioxidant in human health. Environ Health Prev Med 13:102-108

Tobe T, Ueda K, Ando M, Okamoto Y, Kojima N (2015) Thiol-mediated multiple mechanisms centered on selenodiglutathione determine selenium cytotoxicity against MCF-7 cancer cells. J Biol Inorg Chem 20:687-694

Tsuji PA, Carlson BA, Naranjo-Suarez S, Yoo MH, Xu XM, Fomenko DE, Gladyshev VN, Hatfield DL, Davis CD (2012) Knockout of the $15 \mathrm{kDa}$ selenoprotein protects against chemically-induced aberrant crypt formation in mice. PLoS ONE 7:e50574

Tugarova AV, Kamnev AA (2017) Proteins in microbial synthesis of selenium nanoparticles. Talanta 174:539-547

Urig S, Becker K (2006) On the potential of thioredoxin reductase inhibitors for cancer therapy. Semin Cancer Biol 16:452-465

USEPA (2014) ECOTOX User Guide: ECOTOXicology Database System, Version 4.0. U.S. Environmental Protection Agency. https ://www.epa.gov/ecotox/

Valko M, Rhodes CJ, Moncol J, Izakovic M, Mazur M (2006) Free radicals, metals and antioxidants in oxidative stress-induced cancer. Chem Biol Interact 160:1-40

Velnar T, Bailey T, Smrkolj V (2009) The wound healing process: an overview of the cellular and molecular mechanisms. J Int Med Res 37:1528-1542

Vinceti M, Filippini T, Cilloni S, Bargellini A, Vergoni AV, Tsatsakis A, Ferrante M (2017) Health risk assessment of environmental selenium: emerging evidence and challenges. Mol Med Rep 15:3323-3335

Vinceti M, Wei ET, Malagoli C, Bergomi M, Vivoli G (2001) Adverse health effects of selenium in humans. Rev Environ Health $16: 233-251$

Wadhwani SA, Shedbalkar UU, Singh R, Chopade BA (2016) Biogenic selenium nanoparticles: current status and future prospects. Appl Microbiol Biotechnol 100:2555-2566

Walder K, Kantham L, McMillan JS, Trevaskis J, Kerr L, de Silva A, Sunderland T, Godde N, Gao Y, Bishara N, Windmill K (2002) Tanis: a link between type 2 diabetes and inflammation? Diabetes 51:1859-1866

Wallenberg M, Misra S, Wasik AM, Marzano C, Björnstedt M, Gandin V, Fernandes AP (2014) Selenium induces a multi-targeted cell death process in addition to ROS formation. J Cell Mol Med 18:671-684

Wallenberg M, Olm E, Hebert C, Björnstedt M, Fernandes AP (2010) Selenium compounds are substrates for glutaredoxins: a novel pathway for selenium metabolism and a potential mechanism for selenium-mediated cytotoxicity. Biochem J 429:85-93

Wang L, Yang Z, Fu J, Yin H, Xiong K, Tan Q, Jin H, Li J, Wang T, Tang W, Yin J, Cai G, Liu M, Kehr S, Becker K, Zeng H (2012) Ethaselen: a potent mammalian thioredoxin reductase 1 inhibitor 
and novel organoselenium anticancer agent. Free Radic Biol Med 52:898-908

Wang L, Hu H, Wang Z, Xiong H, Cheng Y, Liao JD, Deng Y, Lu J (2014) Methylseleninic acid suppresses pancreatic cancer growth involving multiple pathways. Nutr Cancer 66:295-307

Weisberger AS, Suhrland LG (1956) Studies on analogues of L-cysteine and L-cystine. III. The effect of selenium cystine on leukemia. Blood 11:19-30

Woo HA, Yim SH, Shin DH, Kang D, Yu DY, Rhee SG (2010) Inactivation of peroxiredoxin I by phosphorylation allows localized $\mathrm{H}_{2} \mathrm{O}_{2}$ accumulation for cell signaling. Cell 140:517-528

Wu L, Lanfear J, Harrison PR (1995) The selenium metabolite selenodiglutathione induces cell death by a mechanism distinct from $\mathrm{H}_{2} \mathrm{O}_{2}$ toxicity. Carcinogenesis 16:1579-1584

Wu Q, Rayman MP, Lv H, Schomburg L, Cui B, Gao C, Chen P, Zhuang G, Zhang Z, Peng X, Li H, Zhao Y, He X, Zeng G, Qin F, Hou P, Shi B (2015) Low population selenium status is associated with increased prevalence of thyroid disease. J Clin Endocrinol Metab 100:4037-4047

Wu X, Cao Y, Zhang J, Lei M, Deng X, Zahid KR, Liu Y, Liu K, Yang J, Xiong G, Yao H, Qi C (2016) Determination of glutathione in apoptotic SMMC-7221 cells induced by xylitol selenite using capillary electrophoresis. Biotechnol Lett 38:761-766

Xing F, Li S, Ge X, Wang C, Zeng H, Li D, Dong L (2008) The inhibitory effect of a novel organoselenium compound BBSKE on the tongue cancer Tca8113 in vitro and in vivo. Oral Oncol 44:963-969

Yan J, Guo Y, Wang Y, Mao F, Huang L, Li X (2015) Design, synthesis, and biological evaluation of benzoselenazole-stilbene hybrids as multi-target-directed anticancer agents. Eur J Med Chem 95:220-229

Yang Y, Huang F, Ren Y, Xing L, Wu Y, Li Z, Pan H, Xu C (2009) The anticancer effects of sodium selenite and selenomethionine on human colorectal carcinoma cell lines in nude mice. Oncol Res 18:1-8

Yang Y, Xie Q, Zhao Z, He L, Chan L, Liu Y, Chen Y, Bai M, Pan T, Qu Y, Ling L, Chen T (2017) Functionalized selenium nanosystem as radiation sensitizer of 125I seeds for precise cancer therapy. ACS Appl Mater Interfaces 9:25857-25869

Yant LJ, Ran Q, Rao L, Van Remmen H, Shibatani T, Belter JG, Motta L, Richardson A, Prolla TA (2003) The selenoprotein GPX4 is essential for mouse development and protects from radiation and oxidative damage insults. Free Radic Biol Med 34:496-502

Yao HD, Wu Q, Zhang ZW, Li S, Wang XL, Lei XG, Xu SW (2013) Selenoprotein $\mathrm{W}$ serves as an antioxidant in chicken myoblasts. Biochim Biophys Acta 1830:3112-3120

Yasin M, El-Mehdawi AF, Anwar A, Pilon-Smits EA, Faisal M (2015) Microbial-enhanced selenium and iron biofortification of wheat (Triticumaestivum L.) - applications in phytoremediation and biofortification. Int J Phytoremediation 17:341-347

Ye Y, Shibata Y, Yun C, Ron D, Rapoport TA (2004) A membrane protein complex mediates retro-translocation from the ER lumen into the cytosol. Nature 429:841-847

You Y, Yoo S, Yoon HG, Park J, Lee YH, Kim S, Oh KT, Lee J, Cho HY, Jun W (2010) In vitro and in vivo hepatoprotective effects of the aqueous extract from Taraxacumofficinale (dandelion) root against alcohol-induced oxidative stress. Food Chem Toxicol 48:1632-1637

Yu XZ, Gu JD (2013) Phyto-transport and assimilation of selenium. Plant-based remediation processes. Springer, Berlin, pp 159-175

Zhai X, Zhang C, Zhao G, Stoll S, Ren F, Leng X (2017) Antioxidant capacities of the selenium nanoparticles stabilized by chitosan. J Nanobiotechnol 15:1-12

Zhang L, Zhou L, Du J, Li M, Qian C, Cheng Y, Peng Y, Xie J, Wang D (2014) Induction of apoptosis in human multiple myeloma cell lines by ebselen via enhancing the endogenous reactive oxygen species production. BioMed Res Int 2014:1-10

Zhao F, Yan J, Deng S, Lan L, He F, Kuang B, Zeng H (2006) A thioredoxin reductase inhibitor induces growth inhibition and apoptosis in five cultured human carcinoma cell lines. Cancer Lett 236:46-53

Zhao G, Wu X, Chen P, Zhang L, Yang CS, Zhang J (2018a) Selenium nanoparticles are more efficient than sodium selenite in producing reactive oxygen species and hyper-accumulation of selenium nanoparticles in cancer cells generates potent therapeutic effects. Free Radic Biol Med 126:55-66

Zhao R, Masayasu H, Holmgren A (2002) Ebselen: a substrate for human thioredoxin reductase strongly stimulating its hydroperoxide reductase activity and a superfast thioredoxin oxidant. Proc Natl Acad Sci USA 99:8579-8584

Zhao Y, Sun Q, Zhang X, Baeyens J, Su H (2018b) Self-assembled selenium nanoparticles and their application in the rapid diagnostic detection of small cell lung cancer biomarkers. Soft Matter $14: 481-489$

Zheng X, Zhang Y, Zhang L, Xu W, Ma W, Sun R, Zeng H (2016) Synergistic inhibition of sunitinib and ethaselen against human colorectal cancer cells proliferation. Biomed Pharmacother $83: 212-220$

Zhou M, Ji S, Wu Z, Li Y, Zheng W, Zhou H, Chen T (2015) Synthesis of selenazolopyridine derivatives with capability to induce apoptosis in human breast carcinoma MCF-7 cells through scavenge of intracellular ROS. Eur J Med Chem 96:92-97

Zhu YG, Pilon-Smits EA, Zhao FJ, Williams PN, Meharg AA (2009) Selenium in higher plants: understanding mechanisms for biofortification and phytoremediation. Trends Plant Sci 14:436-442

Zonaro E, Piacenza E, Presentato A, Monti F, DelloAnna R, Lampis S, Vallini G (2017) Ochrobactrum sp. MPV1 from a dump of roasted pyrites can be exploited as bacterial catalyst for the biogenesis of selenium and tellurium nanoparticles. Microb Cell Fact 16:215

Zu K, Bihani T, Lin A, Park YM, Mori K, Ip C (2006) Enhanced selenium effect on growth arrest by BiP/GRP78 knockdown in p53-null human prostate cancer cells. Oncogene 25:546-554

Zubair M, Ali M, Ahmad M, Sajid SM, Ahmad I, Gul ST (2015) Effect of Selenium and Vitamin E on cryopreservation of semen and reproductive performance of animals (a review). J Entomol Zool Stud 3:82-86

Publisher's Note Springer Nature remains neutral with regard to jurisdictional claims in published maps and institutional affiliations. 